\title{
Stability Comparisons between Natural versus Engineered Archaeal Heat-Shock Proteins
}

\section{Mercede Furr ${ }^{1}$, Sreenivasulu Basha ${ }^{2}$, Shilpi Agrawal ${ }^{4}$, Zeina Alraawi ${ }^{4}$, Piyasi Ghosh ${ }^{1,2}$, Carson Stacy ${ }^{1,2}$, T.K.S. Kumar ${ }^{2,4}$, and Ruben Michael Ceballos ${ }^{1,2,3 *}$}

${ }^{1}$ Department of Biological Sciences, University of Arkansas (Fayetteville, AR, USA); ${ }^{2}$ Cell and Molecular Biology Program, University of Arkansas (Fayetteville, AR, USA); ${ }^{3}$ Center for Space and Planetary Sciences (Fayetteville, AR, USA); ${ }^{4}$ Department of Chemistry and Biochemistry, University of Arkansas, Fayetteville, AR 72701, USA.

*To whom all correspondence needs to be addressed. Email: ceballos@uark.edu

\begin{abstract}
Crenarchaeal group II chaperonins (a.k.a., "heat shock" proteins, HSPs) are abundantly expressed in species of the family Sulfolobaceae. HSPa and HSP $\beta$ expression is upregulated during thermal shock. HSPs are subunits of larger octadecameric complexes that function to protect intracellular proteins during thermal stress. Engineered HSPs have been constructed with the idea of protecting enzymes in industrial reactions. HSP $\beta$-coh, a fusion protein comprised of HSP $\beta$ and type 1 cohesin from Clostridium thermocellum was used for proof-of-concept. Dockerin-endowed cellulolytic enzymes bind to the complex via cohesin-dockerin interactions. Enzymatic activity (i.e., hydrolysis of lignocellulose) is retained when the platform is used at high temperatures (e.g., $85-88^{\circ} \mathrm{C}$ ). Moreover, enhancement persists on acid-pretreated substrates prompting the question: Are HSPs acid tolerant? In this study, HSP structural integrity is examined at different temperatures and $\mathrm{pH}$. Far-UV circular dichroism and intrinsic fluorescence indicate HSPa and HSP $\beta$ retain structural integrity at neutral $\mathrm{pH}$ over a range of temperatures $\left(25-90^{\circ} \mathrm{C}\right)$ while $\mathrm{HSP} \beta$-coh is less tolerant to thermal stress. Structural integrity is compromised for all subunits at ultra-low pH (i.e., $\mathrm{pH} 2$ 2) with HSPa showing the most susceptibility. Secondary structures of all HSPs are resilient under mildly acidic conditions ( $\mathrm{pH} 4)$. ANS binding assays indicate a shift in tertiary structure for all subunits at ultra-low $\mathrm{pH}$. Limited trypsin digestion reveals that the backbone of HSP $\beta$-coh is the most flexible and HSP $\beta$ is the most resistant. Results suggest that HSPa and HSP $\beta$ are more resilient than HSP $\beta$-coh under thermal challenge and that there are limits to the acid tolerance of all HSPs.
\end{abstract}

Keywords: Hsp60, tryptophan, conformational changes, acid resistance, structural stability, surface hydrophobicity, thermal transition 


\section{Introduction}

Chaperonin proteins form complexes that function to prevent misfolding and aggregation of other cellular proteins (1-3). Chaperonin complexes are typically large molecular cages ( 1 MDa) that are upregulated during cellular stress (e.g., heat-shock). These molecular cages form ring structures (composed of one or more chaperonin subunit subtypes) that capture misfolded client proteins in an inner cavity (4). Refolding of misfolded substrates is accomplished by closing the chaperonin complex around the client protein. This chaperonin-client protein association perturbs local energy minima in the client protein in a process that involves hydrolysis of adenosine triphosphate (ATP) and divalent cation interactions $(5,6)$. There are two groups of chaperonins. Group I chaperonins (e.g., GroEL/ES) are found in bacteria. The mechanism by which Group I chaperonins and their client proteins interact has been extensively studied (7-9). Group I chaperonins form tetradecamers by end-to-end stacking of heptameric rings thus forming a barrel-like structure within which protein may reside $(10,11)$. GroEL requires a heptameric co-chaperonin, called GroES, to seal the barrel complex and assist in the refolding of the client protein $(3,12)$. Group II chaperonins are found in archaea and eukaryotes. This includes the T-complex protein-1 ring complex (TRiC) or chaperonin-containing TCP-1 (CCT), which is found in eukaryotes. TriC/CCT consists of eight homologous subunits of distinct subtypes: CCT1-8 (13). Group II chaperonins expressed in archaea also form ring structures from subunits known as thermal factors (e.g., TF55, TF56); however, mechanisms of chaperonin-client protein interactions remain elusive. It is known that the archaeal heat shock protein complexes do not require a capping co-chaperone like the GroEL/ES bacterial system (14-16). It is also known that archaeal chaperonin complexes can include at least three chaperonin subtypes: HSPa (TF56), HSP $\beta$ (TF55), and HSPy (17-20) with stoichiometry favoring HSPa/HSP $\beta$ complexes $(4,21)$. However, the most distinguishing feature of these archaeal chaperonins is that those found in hyperthermophilic archaea, such as those of the Order Sulfolobales, function at temperatures exceeding $74^{\circ} \mathrm{C}$. Indeed, multiple species within the family Sulfolobaceae have been isolated from sulfuric geothermal pools and volcanic hot springs at temperatures from $74^{\circ} \mathrm{C}-88^{\circ} \mathrm{C}$ and $\mathrm{pH} 1-4(17,19)$. Although some group II chaperonin complexes can form heptameric or octameric ring structures, chaperonin complexes from Sulfolobales tend to form double nonameric-ring structures $(17,18,22-25)$. It has also been shown that complex formation and subunit expression are upregulated in response to thermal shock $(18,20)$. In in vivo and in vitro experiments $\mathrm{HSPa} / \mathrm{HSP} \beta$ admixtures appear to dominate these heat-shock protein complexes $(17,18,24)$. It has been suggested that HSP $\gamma$ may be a "cold-shock" protein since its incorporation into chaperonin complexes in vitro is actually favored at lower temperatures in the physiological range (14). Studies have shown that HSPa homomers, HSP $\beta$ homomers, and HSPa/HSP $\beta$ heteromers will form in vitro in the presence of ATP and $\mathrm{Mg}^{2+}$. Yet, functional implications of homomeric versus heteromeric complexes and the significance of alternative HSPa:HSP $\beta$ stoichiometries in vivo remain unclear. Whether HSP complexes are homomeric or heteromeric during thermal shock, subunits appear to work together in a highly cooperative manner $(1,3,26)$. It is suggested that function and substrate specificity of archaeal chaperonins is mediated by subunit composition and complex geometry (27).Thus, characterizing the biophysical properties of HSP subunits which form chaperonin complexes may elucidate key structure-function relationships that mediate HSP complex-client protein dynamics under varying environmental conditions (e.g., thermal shock or $\mathrm{pH}$ flux).

Due to the thermotolerance of crenarchaeal group II chaperonins, efforts to use these heat shock proteins in biotechnology has resulted in the design of engineered platforms including complexes composed of subunits which are fusion constructs between HSPs and accessory proteins (28-31). One such effort features the fusion of cohesin (Type I) from the bacterium Clostridium thermocellum to a circular permutant of HSP $\beta$ derived from Sulfolobus shibatae $(28,30)$. The resulting HSP $\beta$-cohesin (HSP $\beta$-coh) fusion protein was shown in vitro to form double nonameric-ring (18-mer) complexes resembling natural thermosomes. This engineered prototype complex was called a rosettasome (28) and was used to bind cellulases from $C$. thermocellulum via cohesion (fused to HSP $\beta$ ) and dockerin (Type 1) found as a functional domain on cellulolytic enzymes of the $C$. thermocellum cellulosome. The rosettasome bound with cellulolytic enzymes (a.k.a., the rosettazyme) was shown to more efficiently breakdown Avicel $^{\circledR}$ than free enzyme in solution absent the chaperonin-based platform (28). 
Thereafter, this engineered construct was shown to improve hydrolytic efficiency on acid- and alkalinetreated lignocellulosic biomass (30). Although catalytic activity of enzymes bound to the engineered platform resulted in a 2- to 3-fold increase in hydrolysis of carbohydrates (i.e., cellulose, hemicellulose) on pretreated corn pericarp and wheat straw substrates (30), a technology transfer assessment concluded that a 6 - to 10 -fold enhancement of enzymatic efficiency is required for economic viability. This level of enhancement could not be accomplished solely by varying enzyme complement. Therefore, the core platform (i.e., engineered complex) required re-design, testing, and optimization. This resulted in the construction of a next-generation mobile enzyme sequestration platform (MESP)

As in prior work, MESPs appear to enhance enzymatic efficiency on acid-pretreated substrates. Although the thermotolerance of engineered platforms was anticipated, the enhanced enzymatic efficiency on acid-treated substrate was not. This result suggested that MESPs may be acid-tolerant. Despite surviving in acidic geothermal habitats at $\mathrm{pH}<4$, the intracellular environment of Sulfolobales is reported to be at a $\mathrm{pH}$ of $\sim 6.5(32,33)$. Therefore, there was no expectation of HSP acid tolerance. In the present study, we analyze the relative stability of natural HSPs (HSPa and HSP $\beta$ ) and the engineered construct (i.e., HSP $\beta$-coh) under different conditions of $\mathrm{pH}$ and temperature using a variety of biophysical methods to determine the limits of the acid and thermal tolerance of these proteins.

\section{Results}

\section{Silver staining confirms purity of HSP protein working stocks}

Using sodium dodecyl sulphate-polyacrylamide gel electrophoresis (SDS-PAGE) and silver staining, purified $\mathrm{HSP} \alpha, \mathrm{HSP} \beta$, and $\mathrm{HSP} \beta$-coh subunits were compared to a broad-range pre-stained ladder. HSP $\alpha$ and HSP $\beta$ produce $\sim 60 \mathrm{kDa}$ bands and the larger HSP $\beta$-coh fusion construct produces a band at $\sim 73 \mathrm{kDa}$ (Fig. S1), which is consistent with the molecular weights derived from the ExPASy ProtParam server (34). HSPa and HSP $\beta$ differ, in terms of length, by 8 residues, with 560 and 552 amino acids, respectively. The molecular weight of the engineered HSP $\beta$-coh fusion protein is higher at $73 \mathrm{kDa}$ with 660 amino acids. Mass spectroscopy (i.e., MALDI-TOF MS) was employed (Fig. S2) to confirm the primary structure of all HSPs (i.e., amino acid sequences).

\section{Modeling predicts structural organization of HSP subunits}

Upon resolving the primary structures of each of the HSP subunits (i.e., HSPa, HSP $\beta$, and HSP $\beta$-coh), the primary sequences were used to generate structural models (see Fig. 1) in PyMOL 2.4 (https://pymol.org) (35). Structural models for HSPa and HSP $\beta$ exhibit similar three-dimensional structures (Fig. 1A, B). These data were used to compare secondary structures (i.e., $\alpha$-helices, $\beta$ sheets, loops, and turns), hydrophobic segments, conserved regions, and three functional domains (i.e., apical, intermediate, and equatorial domains). In general, all three HSP subunits appear to be helix-rich structures with 16 a-helices, $18 \beta$-strands, and a characteristic stem loop between the intermediate and equatorial domains, which is consistent with higher resolution models previously reported (4). These domains show structural similarities to the GroEL superfamily of group I chaperonins in bacteria (27). Results from multiple sequence alignments of the engineered HSP $\beta$-coh show $42 \%$ and $66 \%$ sequence similarity with the natural HSPa and HSP $\beta$ chaperonins, respectively. Out of the 560 amino acids that comprise natural $\mathrm{HSPa}$, it is estimated that $52.68 \%$ are found in $\alpha$ helices and $14.29 \%$ in $\beta$-strands. Likewise, out of the 552 amino acids that comprise natural HSP $\beta$, it is estimated that $53.08 \%$ are found in $\alpha$-helices and $14.49 \%$ in $\beta$-strands. Apical domains for HSPa and HSP $\beta$ each resolve from a contiguous stretch of residues. However, the equatorial and intermediate domains for HSPa and HSP $\beta$ form from the convergence of multiple stretches of amino acids and the resulting intermingled secondary structural elements. 


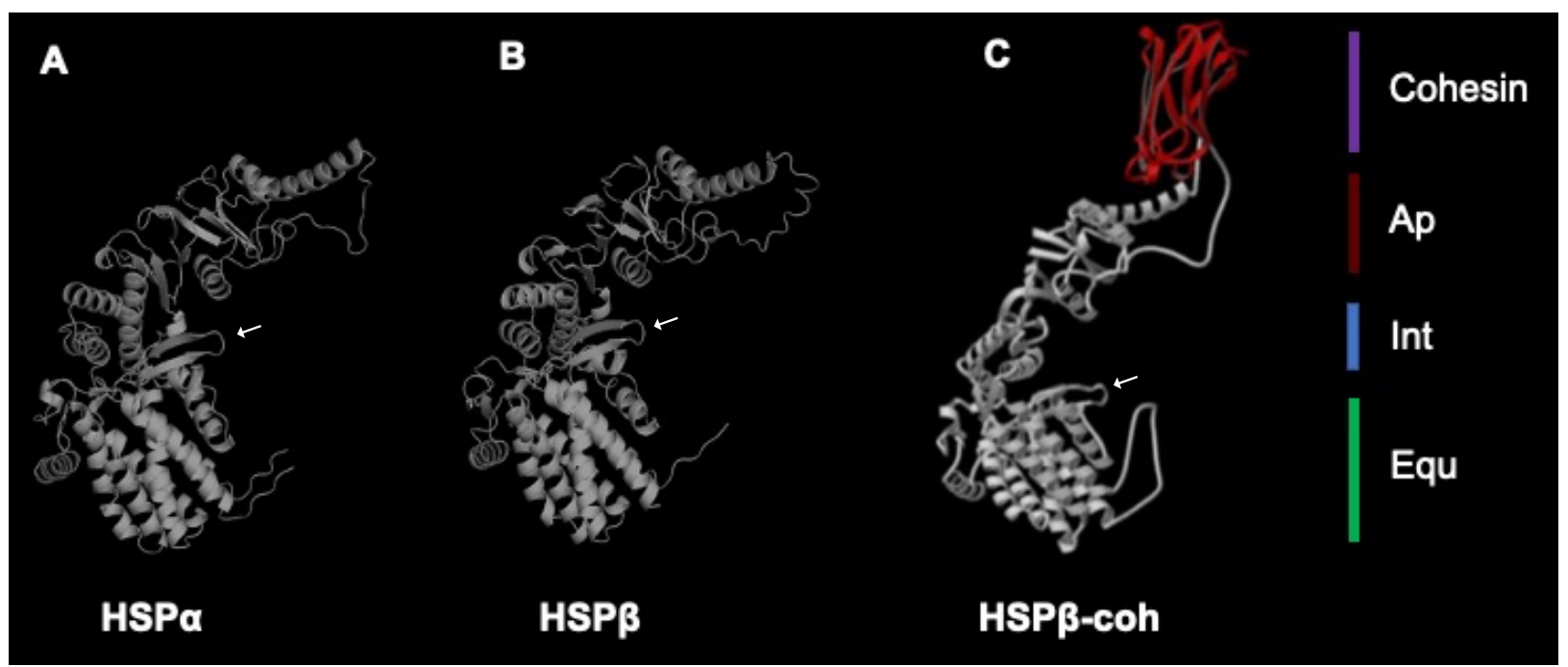

Figure 1. Structural models of natural and engineered HSP subunits. (A) 3-D structural model of the HSPa subunit; (B) structural model of HSPB; (C) structural model of the engineered HSP $\beta$-coh (adapted from Mitsuzawa et al., 2009). Homologous apical (maroon), intermediate (blue), and equatorial (green) domains are shown by section bars (right). Characteristic stem loop between equatorial and intermediate domain is present on all the three subunits (white arrow).

All HSP subunits exhibit comparable tertiary structures. The base structure of HSP $\beta$-coh resembles $\mathrm{HSP} \alpha$ and HSP $\beta$ but includes the cohesin extending from the apex of the HSP $\beta$ permutant (Fig. 1C). Each model reveals a three-dimensional structure with apical, intermediate, and equatorial domains. The cohesin domain fused to the HSP $\beta$ circular permutant (i.e., HSP $\beta$-coh) provides an interaction site for dockerin (type 1) found on $C$. thermocellum cellulases, xylanases, and dockerin-endowed engineered fusion protein (i.e., enzyme) constructs (36). Since HSP $\beta$-coh is based on the fusion of cohesin to a circular permutant of HSP $\beta$, the location of residues comprising key secondary structure elements is shifted. Still, the number of $\alpha$-helices and $\beta$-strands (as well as their relative positions in the tertiary structure of the folded protein) remains conserved. HSP $\beta$-coh exhibits $16 \alpha$-helices, $18 \beta$ strands, and the aforementioned characteristic HSP stem loop. In HSPa, the stem loop resolves at residues 46-58 (KMLIDSFGDVTIT). In HSP 3 , the stem loop is located from positions 56-68 (KMFVDSLGDITIT). In HSPß-coh the stem loop resolves at residues 315-327(KILVDSLGITIT). This HSP stem loop structure, which is also present in group I chaperonins (i.e., GroEL/ES), features an ATP binding site, which is critical for chaperonin function (37).

Alignment of $\mathrm{HSPa}, \mathrm{HSP} \beta$, and $\mathrm{HSP} \beta$-coh reveals other highly conserved stretches of amino acid sequences between 57 - 73, 36-48 and 85-93 for HSPa, 95-103, 46-58 and 67-83 for HSP $\beta$ and 355362, 316-332 and 325-341 for HSP $\beta$-coh (Fig. 2), including notable hydrophobic regions. As part of the HSP $\beta$-coh fusion construct two linkers are present in the primary structure (Fig. 2, orange icons). One linker at position 265-270 was engineered to alter the position of the $\mathrm{N}$-terminus and C-terminus in the development of the permutant. The second linker shown at position 526-534 was added to fuse cohesin (type 1) from $C$. thermocellum to the $S$. shibatae HSP $\beta$ permutant. For experiments in this study the 9-residue linker form of HSP $\beta$-coh was used. However, other linker lengths are also available (data not shown). Likewise, other HSP $\beta$ circular permutants are available. Changing the position of cohesin using different circular permutants and the HSP $\beta$-coh linker length provides opportunities to study HSP complex-client protein interactions and the role of linker length in preventing steric interference between enzymes bound to the MESP. (These alterations will be reported separately). 
bioRxiv preprint doi: https://doi.org/10.1101/2021.08.21.457208; this version posted August 22, 2021. The copyright holder for this preprint (which was not certified by peer review) is the author/funder, who has granted bioRxiv a license to display the preprint in perpetuity. It is made available under aCC-BY-NC-ND 4.0 International license.

HSP Q

HSP $\beta$

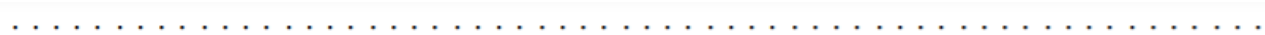

HSP $\beta$ cohesin MADPT QMHKFLEEEENILKEKVDKIAATGANVVIAQKGIDEVAQHYLAKKGILAVRRAKK

$\operatorname{HSP} \alpha$

HSP $\beta$

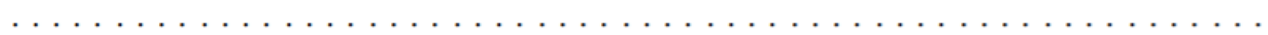

HSP $\beta$ cohesin SDLEKLARATGGRVISNIDELTSQDLGYAALVEERKVGEDKIVFVEGAKNPKSVSILIRG

HSP $\alpha$

HSP $\beta$

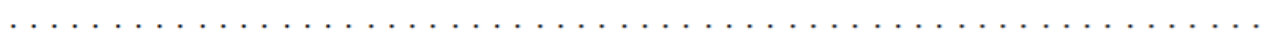

HSP $\beta$ cohesin GLERVVDETERALRDALGTVADVIRDGRAVAGGGAVEIEIAKRLRKYAPQVGGKEQLAIE

HSP $\alpha$

HSP $\beta$

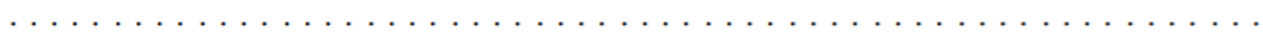

HSP $\beta$ cohesin AYANAIEGLIMILAENAGLDPIDKLMQLRSLHENETNKWYGLNLFTGNPEDMWKLGVIEP

HSP $\alpha$

HSP $\boldsymbol{\beta}$

elebleleble

31

41

300

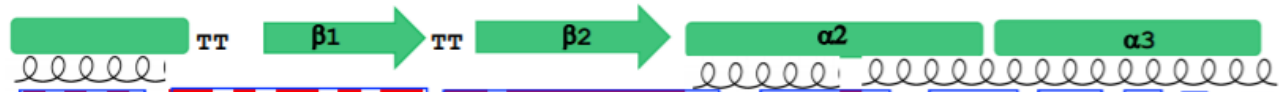

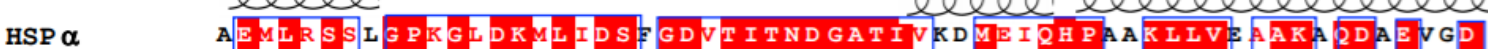
HSP $\beta$ EEALKSTYGPRGMDKMVDS GDITITNDGATILDKMDLQHPTGKLLVRIAKG 2DEETAD HSP $\beta$ cohesin EEALKSTYGPRGMDKILVDS GDITITNDGATILDKMDLQHPTGKLLVRIAKG LDEETAD A

HSP $\alpha$ GTISAVVLAGALIERAESLLPQNIHPTIITEGYKKAYTKALELIPQTEFRIDTRDLNSSV HSP $\beta$ GTKTAVILAGELAKAEDLLYKEIHPTIIVSGYKKAEEIALKTIQDIAQPVSIND.... HSP $\beta$ cohesin GTKTAVILAGELAKKAEDLLYKEIHPTIIVSGYKKAEEIALKTIQDIAQPVSIN ..... $\boldsymbol{B}$

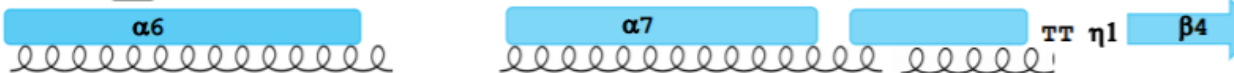
HSP $\alpha$ ARDTLRKIAFTTLASKFIAEGAELNKIDMVIDAIVNVAEPLPNGGMNFSIDHIKIDKKK

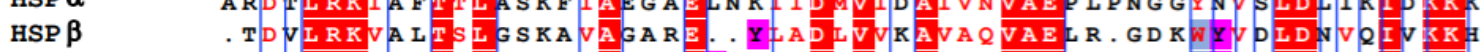
HSP $\beta$ cohesin DTDVLRKVALTSLGSKAVAGAREY. . AADUVVKAVAQVAELR. GDKWYVLDNVQIVKK

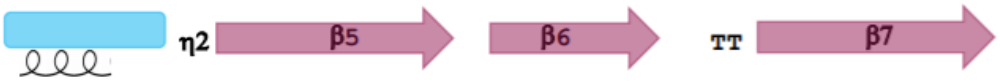

HSP $\boldsymbol{\alpha}$ GGSIEDSVIVKGLVLDKEVVHPGMPRRVTKAKIAVLDAALEVEKPEISAKISITSPEQIK HSP $\boldsymbol{\beta}$ GGSINDTQLVYGIVVDKEVVHPGMPKRIENAKIALLDASLEVEKPELDAEIRINDPTQMH HSP $\beta$ cohesin GGSIN Q

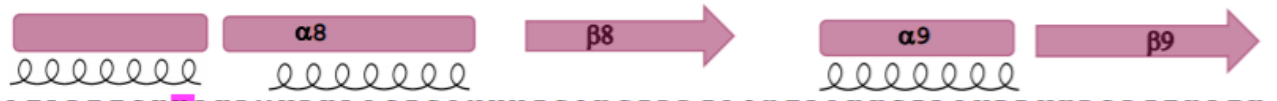

HSP $\alpha$ AFLDEESKYLKDMVDKLASIGANVVICQKGIDDIAQHFLAKKGILAVRRVKRSDIEKLEK HSP $\beta$ KFLEEEENILKEKVDKIAATGANVVICQKGIDEVAQHYLAKKGILAVRRAKKSDLEKLAR 


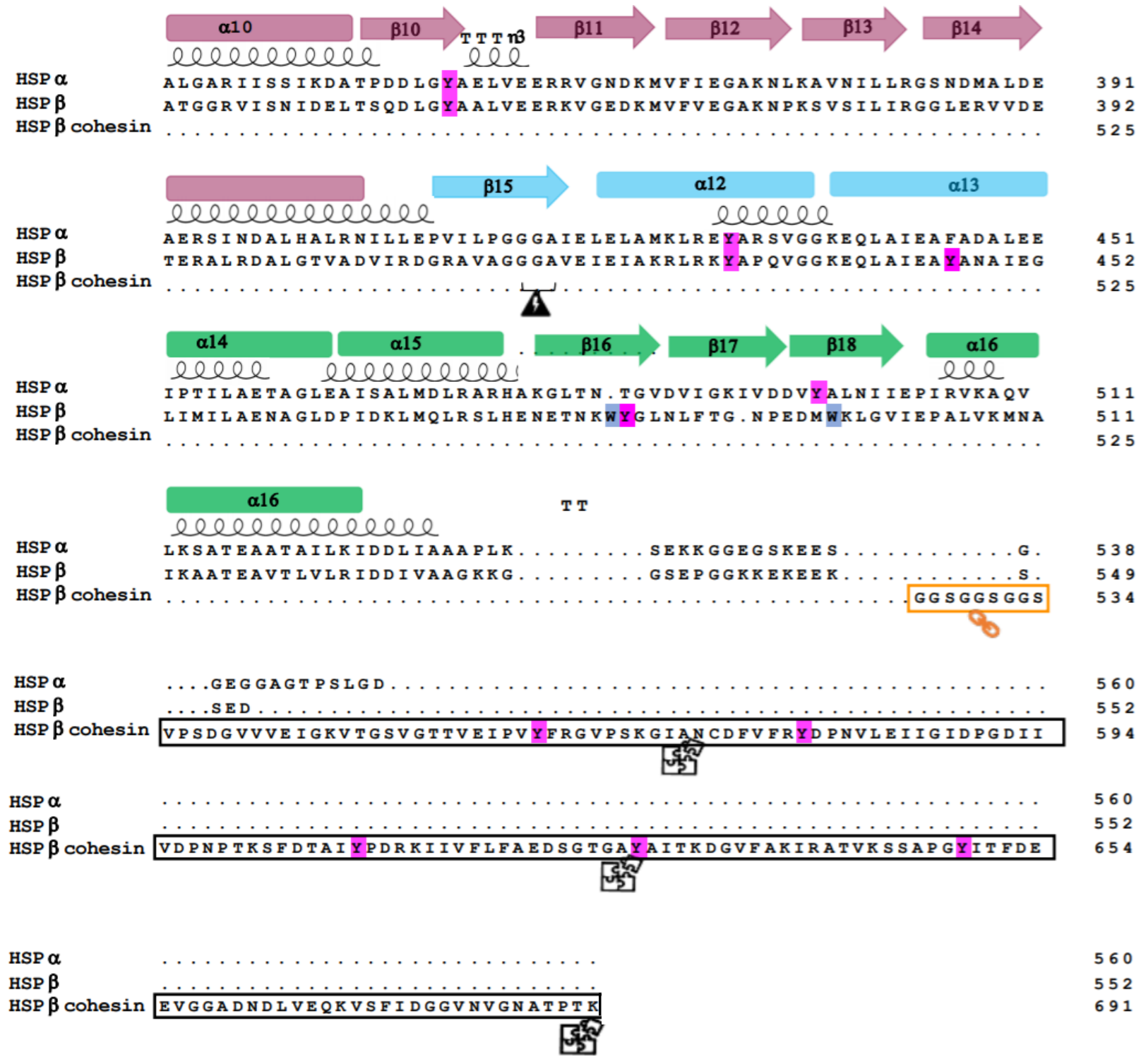

Apical domain
Intermediate domain
S Cohesin module from CipA

Figure 2. Primary sequence alignment of HSPa, HSP $\beta$, and HSP $\beta$-coh. Multiple sequence alignment was generated using ClustalW (38) and visualized by ESPript (39). The $\alpha$-helices and $\beta$-strands are represented as coils and arrows, respectively. $\beta$-turns are marked noted as TT. Conserved regions are marked in blue boxes and the residues are highlighted in red. The linker at the amino acid position 267 of HSP $\beta$ and between HSP $\beta$ and the cohesion moiety is marked with an orange box. The domains are color coded: apical (magenta), intermediate (blue), and equatorial (green). The stem loop region is denoted by a purple triangle. Tyrosine residues are highlighted in purple and tryptophan residues are highlighted in blue. 


\section{Differential Scanning Calorimetry (DSC) reveals high thermal stability of HSP subunits}

DSC is an analytical tool commonly used for determining the thermal stability of proteins by measuring changes in heat capacity (40). DSC was employed to assess the limits of the HSP subunit thermal stabilities. Specifically, $\mathrm{HSPa}, \mathrm{HSP}$, and $\mathrm{HSP} \beta$-coh were each subjected to temperatures from $25^{\circ} \mathrm{C}$ $-110^{\circ} \mathrm{C}$. Readings were recorded at $5^{\circ} \mathrm{C}$ increments. The melting temperature $\left(\mathrm{T}_{\mathrm{m}}\right)$ at which $50 \%$ of the protein exists in denatured or unfolded states was calculated. $T_{m}$ thresholds of HSPa, HSP $\beta$, and HSP $\beta$-coh were determined under different $\mathrm{pH}$ conditions $(2,4$, and 7$)$. Tm for HSPa, HSP , and $\mathrm{HSP} \beta$-coh at $\mathrm{pH} 7$ were determined to be $93.6^{\circ} \mathrm{C}, 93.6^{\circ} \mathrm{C}$, and $88.3^{\circ} \mathrm{C}$, respectively (Fig. 3). On the contrary, $\mathrm{Tm}$ of HSPa at pH 2 and 4 shifts from $93^{\circ} \mathrm{C}$ to $68.2^{\circ} \mathrm{C}$ and $69.4^{\circ} \mathrm{C}$, respectively, whereas $\mathrm{Tm}$ of $\mathrm{HSP} \beta$ at $\mathrm{pH} 2$ and 4 shifts from $93.0^{\circ} \mathrm{C}$ to $58.5^{\circ} \mathrm{C}$ and $57.0^{\circ} \mathrm{C}$, respectively (Fig. 3). $\mathrm{Tm}$ of HSP $\beta$-coh shifts from $88.3^{\circ} \mathrm{C}$ at pH 7 to $67.5^{\circ} \mathrm{C}$ and $66.0^{\circ} \mathrm{C}$ at pH 2 and 4 , respectively (Fig. 3).

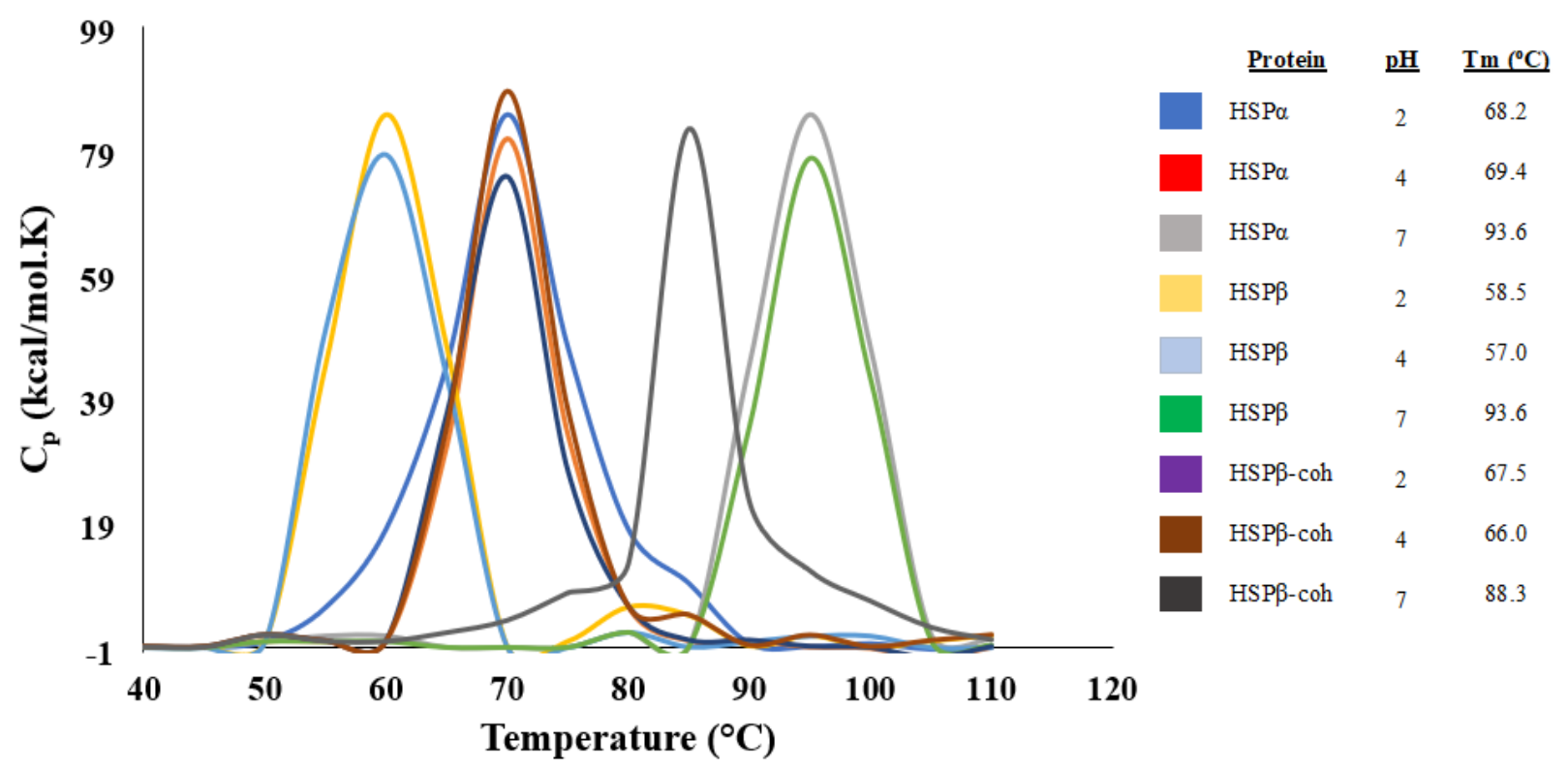

Figure 3. Differential Scanning Calorimetry of HSP subunits. Analysis of the thermodynamic stabilities of HSPa, $\mathrm{HSP} \beta$, and HSP $\beta$-coh monitored by DSC under three different pH conditions: HSPa pH 2 (red), HSPa pH 4 (purple), $\mathrm{HSP} \alpha \mathrm{pH} 7$ (orange), HSP $\beta$ pH 2 (magenta), HSP $\beta$ at pH 4 (green), HSP $\beta \mathrm{pH} 7$ (cyan), HSP $\beta$-coh pH 2 (brown), HSP $\beta$ coh pH 4 (blue), and $\mathrm{HSP} \beta$-coh pH 7 (black).

\section{Integrity of the secondary structures of HSP subunits at different temperatures}

To determine the stability of secondary structural elements (e.g., a-helices) under varying conditions of $\mathrm{pH}$ and temperature, far-UV circular dichroism (CD) spectroscopy experiments were conducted for each subunit. The CD spectra for each HSP subunit reveals two hypo-elliptical bands around $208 \mathrm{~nm}$ and $222 \mathrm{~nm}$ (see Fig. 4), which is characteristic of helical-rich protein backbone structures $(41,42)$. The changes in circular dichroism spectra have been examined as a function of temperature and $\mathrm{pH}$. At neutral $\mathrm{pH}(\mathrm{pH} 7)$, varying temperature does not significantly impact the secondary structure of $\mathrm{HSP} \alpha, \mathrm{HSP} \beta$ or HSP $\beta$-coh (Fig. 4A). The thermal denaturation CD spectral overlays of HSPa, HSP $\beta$, and $\mathrm{HSP} \beta$-coh at $\mathrm{pH} 7$ superimpose with one another with negligible deviation (Fig. 4A). Since HSPs have evolved in thermophilic environments with intracellular $\mathrm{pH}$ typically around 6.5-6.8 $(32,33)$, it is suggested that neutral $\mathrm{pH}$ trials at the higher end of the temperature range $\left(75^{\circ} \mathrm{C}-80^{\circ} \mathrm{C}\right)$ best represent the native structural state. The magnitude of molar ellipticity decreases as temperature increases at $\mathrm{pH} 2$ and 4 for $\mathrm{HSPa}$ and at $\mathrm{pH} 2$ for HSPB-coh (Fig. 4B-C). Minor spectral shifts along the x-axis (i.e., wavelength) were also observed at $\mathrm{pH} 2$ and 4 for $\mathrm{HSPa}$ (Fig. 4C). 


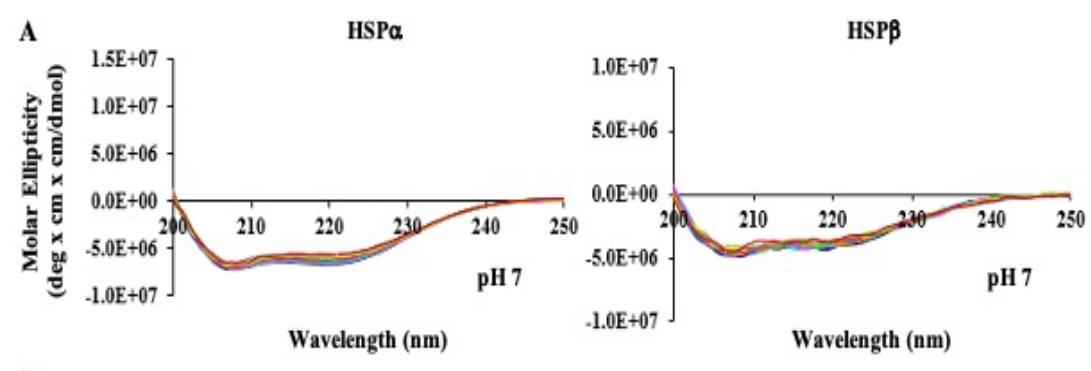

B
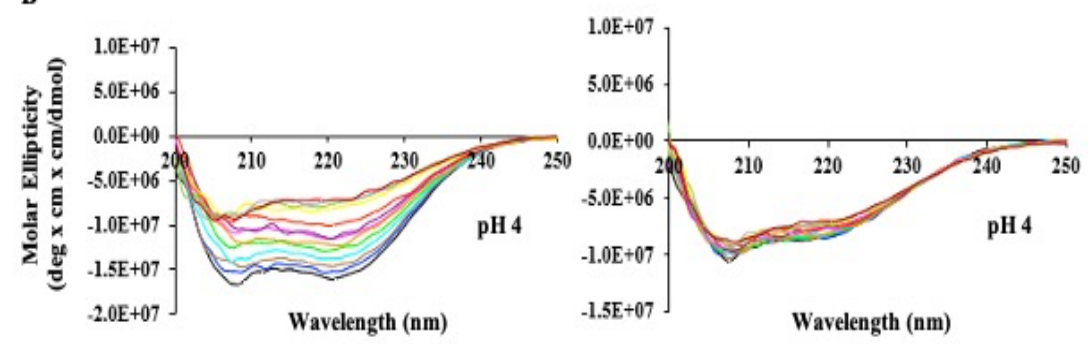

C
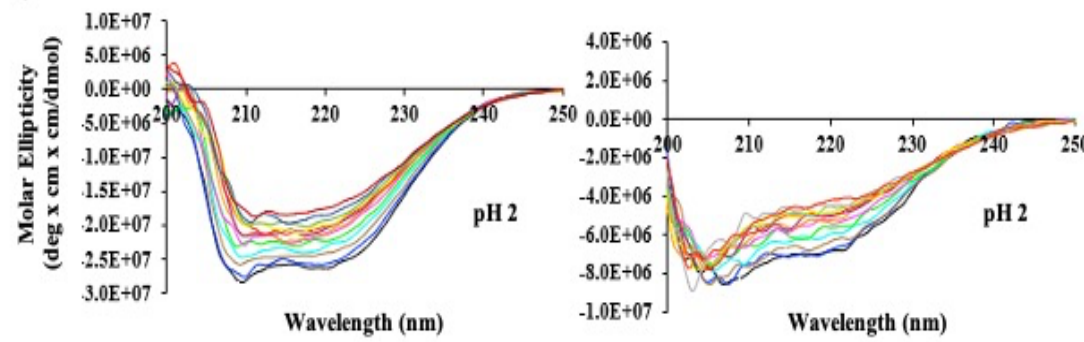

HSPB-coh
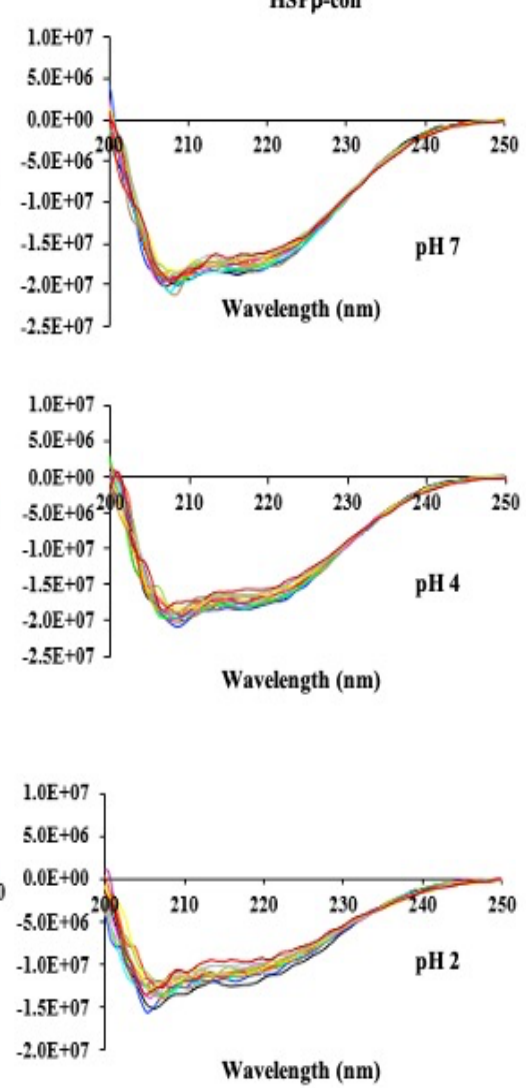

Figure 4. Far-UV Circular Dichroism (CD) spectra of HSPs. HSPa (Left), HSP (Middle), and HSP -coh (Right) upon thermal denaturation $\left(25-90^{\circ} \mathrm{C}\right)$ at $(\mathrm{A}) \mathrm{pH} 7,(\mathrm{~B}) \mathrm{pH} 4$, and $(\mathrm{C}) \mathrm{pH}$ 2. Color coding is the same for each spectrum overlay: $25^{\circ} \mathrm{C}$ (black), $30^{\circ} \mathrm{C}$ (blue), $35^{\circ} \mathrm{C}$ (brown), $40^{\circ} \mathrm{C}$ (teal), $45^{\circ} \mathrm{C}$ (neon green), $50^{\circ} \mathrm{C}$ (pink), $55^{\circ} \mathrm{C}$ (orange), $60^{\circ} \mathrm{C}$ (purple), $65^{\circ} \mathrm{C}$ (red), $70^{\circ} \mathrm{C}$ (yellow), $75^{\circ} \mathrm{C}$ (green), $80^{\circ} \mathrm{C}$ (grey), $85^{\circ} \mathrm{C}$ (maroon).

Calculating the weighted spectral difference (WSD) provides a detailed method for quantifying spectral differences in CD data (43). WSD was employed to provide a more precise comparison of the spectral similarities and dissimilarities between subunits under varying conditions. Again, we consider the spectra at $\mathrm{pH} 7$ and $75^{\circ} \mathrm{C}$ to be representative of the native conformation for each HSP subunit. All subunits show similarity across the temperature range of $25-90^{\circ} \mathrm{C}$ at $\mathrm{pH}$. This is represented by the overlap of WSD values in blue (Fig.5). Interestingly, the thermal denaturation spectra of HSP $\beta$-coh at $\mathrm{pH} 4$ also overlaps with the representative native conformation spectra of all three subunits at $\mathrm{pH} 7$. However, the thermal denaturation spectra of HSP $\beta$ at $\mathrm{pH} 4$ and 2 reveal a decrease in magnitude. Although the WSD values derived from the thermal denaturation spectra of HSPa deviates the most from the native conformation of itself and the other subunits at $\mathrm{pH} 2$, all the subunits, at $\mathrm{pH} 2$, show dissimilarity when compared to the native conformation spectra. (Fig.5, indicated in red). Analysis of WSD across temperature and $\mathrm{pH}$ ranges indicate changes in $\mathrm{pH}$ have a larger effect on the secondary structure of each HSP than changes in temperature (Fig. 5). One exception to this trend was seen with $\mathrm{HSP} \beta$-coh at $\mathrm{pH} 4$ closely matching the trend curves at $\mathrm{pH} 7$ across the range of temperatures. A negative correlation was seen between temperature and WSD for HSP $\beta$ in low $\mathrm{pH}$ conditions. These results suggest that, in terms of secondary structural stability, HSPa is more sensitive to changes in $\mathrm{pH}$ and temperature than HSP $\beta$ or HSP $\beta$-coh. Despite apparent sensitivity to low $\mathrm{pH}$, results suggest thermal stability for $\mathrm{HSPa}, \mathrm{HSP} \beta$, and $\mathrm{HSP} \beta$-coh up to $85^{\circ} \mathrm{C}$. 


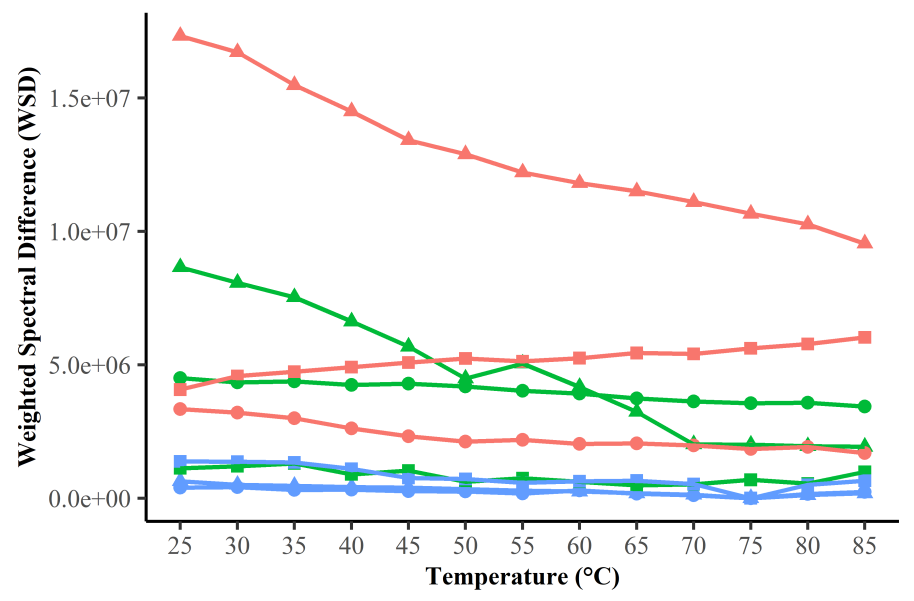

Figure 5. Weighted Spectral Difference (WSD). WSD of Far-UV Circular Dichroism (CD) spectra for HSPs. HSPa ( $\mathbf{\Delta}), \operatorname{HSP} \beta(\bullet)$, and $\mathrm{HSP} \beta$-coh (-) at pH 2 (red), $\mathrm{pH} 4$ (green), and $\mathrm{pH} 7$ (blue). Each point indicates the calculated WSD between the spectra of a given combination of protein, $\mathrm{pH}$ and temperature and the spectra of the same protein at $\mathrm{pH}=7$ and $\mathrm{T}=75^{\circ} \mathrm{C}$.

Although CD spectra for HSPa exhibited the most significant decrease in magnitude at lower $\mathrm{pH}$, the general spectral profile remained. To determine if these shifts represent significant changes in secondary structure, the $222 / 208 \mathrm{~nm}$ ratio was plotted for each spectrum as a function of temperature (by $\mathrm{pH}$ condition) for each HSP (Fig. 6). The ratio of the molar ellipticities at $222 \mathrm{~nm}$ and $208 \mathrm{~nm}$ $([\theta] 222 /[\theta] 208)$ is utilized as a criterion to evaluate the presence of coiled-coil helices in proteins (44). A non-interacting $\alpha$-helix presents a ratio at 0.9 or below, while ratios of 1.0 or above indicate the presence of coiled-coil helices $(45,46)$. The effect of varying the temperature and $\mathrm{pH}$ of the natural and engineered HSP subunits on the $[\theta] 222 /[\theta] 208$ ratio was examined, to determine if coiled-coil formation occurs due to fluctuations in temperature and $\mathrm{pH}$. The ratio remained unaltered (below 0.9 ) for all three subunits at $\mathrm{pH} 7$ over temperatures ranging from $25-85^{\circ} \mathrm{C}$ (Fig. 6). There is no overt alteration in the ratio for $\mathrm{HSP} \beta$ and $\mathrm{HSP} \beta$-coh in the lower $\mathrm{pH}$ range (2 and 4) (Fig. 6). For $\mathrm{HSPa}$, induction of coiled-coil helices appears to take place over the temperature range of $40-85^{\circ} \mathrm{C}$ at $\mathrm{pH} 2$ as indicated by a shift in 222/208 $\mathrm{nm}$ to 1.0 (and above). The emergence of coiled-coil structures within $\mathrm{HSPa}$ at $\mathrm{pH} 4$ appears to take place from $30-65^{\circ} \mathrm{C}$.

A

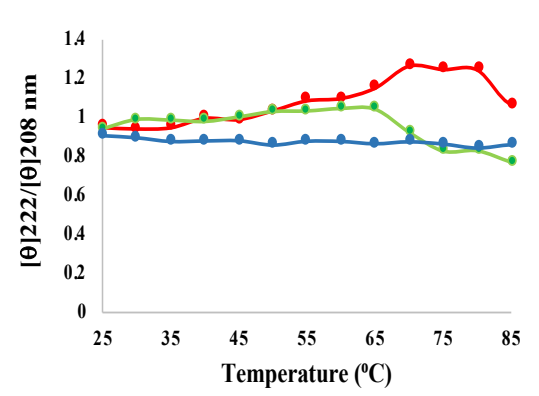

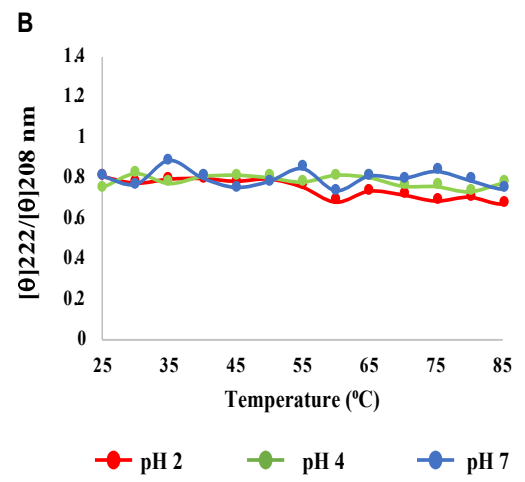

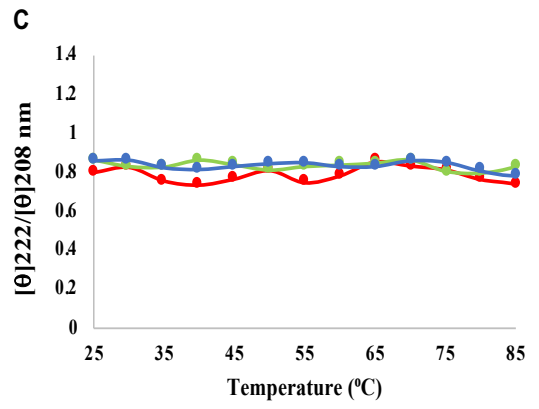

Figure 6. Ratio plots for HSP subunit CD data. Plots of $[\theta] 222 /[\theta] 208 \mathrm{~nm}$ as a function of temperature and $\mathrm{pH}$ for (A) $H S P \alpha,(B) H S P \beta$, and (C) HSP $\beta$-coh. 
Intrinsic protein fluorescence, predominately due to the fluorescent emission of tryptophan when excited at $280 \mathrm{~nm}$, is a useful method to probe tertiary structural changes in proteins by providing information on stability and folding/unfolding states $(47,48)$. Tryptophan fluorescence is sensitive to solvent polarity. Tryptophan residue(s) present on the surface of the protein are exposed to polar solvent whereas tryptophan residue(s) buried deep within a protein are shielded away from the polar environment. As the polarity of solvent increases, typically the fluorescence maxima goes through a red shift and the quantum yield decreases (49). However, in some cases, the tryptophan fluorescence of a protein may be quenched due to quenching by other residues (49). HSPa does not contain any tryptophan residues. The native conformation shows an emission maximum at $306 \mathrm{~nm}$ corresponding to the seven tyrosine residues in the protein located across all three domains: Y280, Y351 (apical); Y198, Y496 (intermediate); and Y124, Y128, Y430 (equatorial). For intrinsic fluorescence readings, $\mathrm{HSP} \alpha$ was subjected to a pH range of $2-9$ and held at temperatures $75^{\circ} \mathrm{C}, 80^{\circ} \mathrm{C}$, and $90^{\circ} \mathrm{C}(\mathrm{Fig} .7 \mathrm{~A})$. Intrinsic fluorescence spectra of $\mathrm{HSPa}$, across the $\mathrm{pH}$ range, show a maximum emission at $\sim 306 \mathrm{~nm}$, which is consistent with the native conformation of the protein (Fig. 7A). The environment of the fluorophores for HSPa remained unchanged as the emission maxima fluctuated only slightly by 2-4 $\mathrm{nm}$ with the exception of $\mathrm{HSPa}$ at $75^{\circ} \mathrm{C}$ and the higher $\mathrm{pH}$ range $(\mathrm{pH} 8$ and 9) wherein the protein shows emission maxima shift closer to $350 \mathrm{~nm}$. However, the fluorescence spectra of $\mathrm{HSPa}$, under most conditions, show a small hump at $350 \mathrm{~nm}$ in addition to the more prominent emission maxima peak at $306 \mathrm{~nm}$. This suggests that a subtle perturbation of the tertiary structure occurs due to temperature and $\mathrm{pH}$ fluctuations. The relative fluorescence intensity (RFI) is lower at lower $\mathrm{pH}$ conditions ( $\mathrm{pH} 2$ and 3 ) across all temperatures (physiological and heat shock). The decrease in intensity could be associated with an increase in compactness (supercoiling of helices), therefore resulting in a more buried environment of the fluorophores. This would decrease the exposure to solvent therefore decreasing emission. Overall, temperature and $\mathrm{pH}$ conditions did not lead to significant perturbations in the tertiary structure of HSPa.

HSP $\beta$ contains three tryptophan residues and 12 tyrosine residues located across the three domains: Y310, Y352 (apical); W198, Y199, Y223 (intermediate); and Y26, Y49, Y122, Y134, Y431, W433, Y446, Y484, W497 (equatorial). The emission maximum is at $340 \mathrm{~nm}$ in neutral $\mathrm{pH}$ over the range of temperatures $\left(75^{\circ} \mathrm{C}, 80^{\circ} \mathrm{C}\right.$, and $\left.90^{\circ} \mathrm{C}\right)$ suggesting that the folded state of the protein is relatively stable and that tryptophan residues for HSP $\beta$ are partially accessible to solvent in its native conformation. No significant changes in emission maxima were observed for HSP $\beta$ over this range of $\mathrm{pH}$ at $75^{\circ} \mathrm{C}$ (Fig. 7B) except for at $\mathrm{pH} 3$ wherein the emission maximum decreased to $332 \mathrm{~nm}$. At $80^{\circ} \mathrm{C}$, the emission maximum for all $\mathrm{pH}$ conditions except for neutral $\mathrm{pH}(\mathrm{pH} 7)$ shifted slightly by $2 \mathrm{~nm}$. At $90^{\circ} \mathrm{C}$, all emission maximum values went through a slight red shift of 2-4 $\mathrm{nm}$. Again, the observed RFI is lower at $\mathrm{pH} 2$ and 3 across all temperatures. As the emission maximum decreases, this suggests the fluorophores may have shifted to a more apolar core perhaps due to helical content increase.

Like HSP $\beta$, HSP $\beta$-coh also only contains three tryptophan residues. No additional tryptophan residues are introduced due to fusion of the cohesin to the HSP $\beta$ circular permutant. The emission maximum for $\mathrm{HSP} \beta$-coh is $\sim 334 \mathrm{~nm}$ in neutral $\mathrm{pH}$ over the range of temperatures $\left(75^{\circ} \mathrm{C}, 80^{\circ} \mathrm{C}\right.$, and $\left.90^{\circ} \mathrm{C}\right)$. Interestingly, at $\mathrm{pH} 2$ and 3 , and over the full range temperatures $\left(75^{\circ} \mathrm{C}, 80^{\circ} \mathrm{C}\right.$, and $\left.90^{\circ} \mathrm{C}\right), \mathrm{HSP} \beta$-coh exhibits a blue shift, as well as a lowered RFI consistent with the other HSPs (Fig. 7C). 

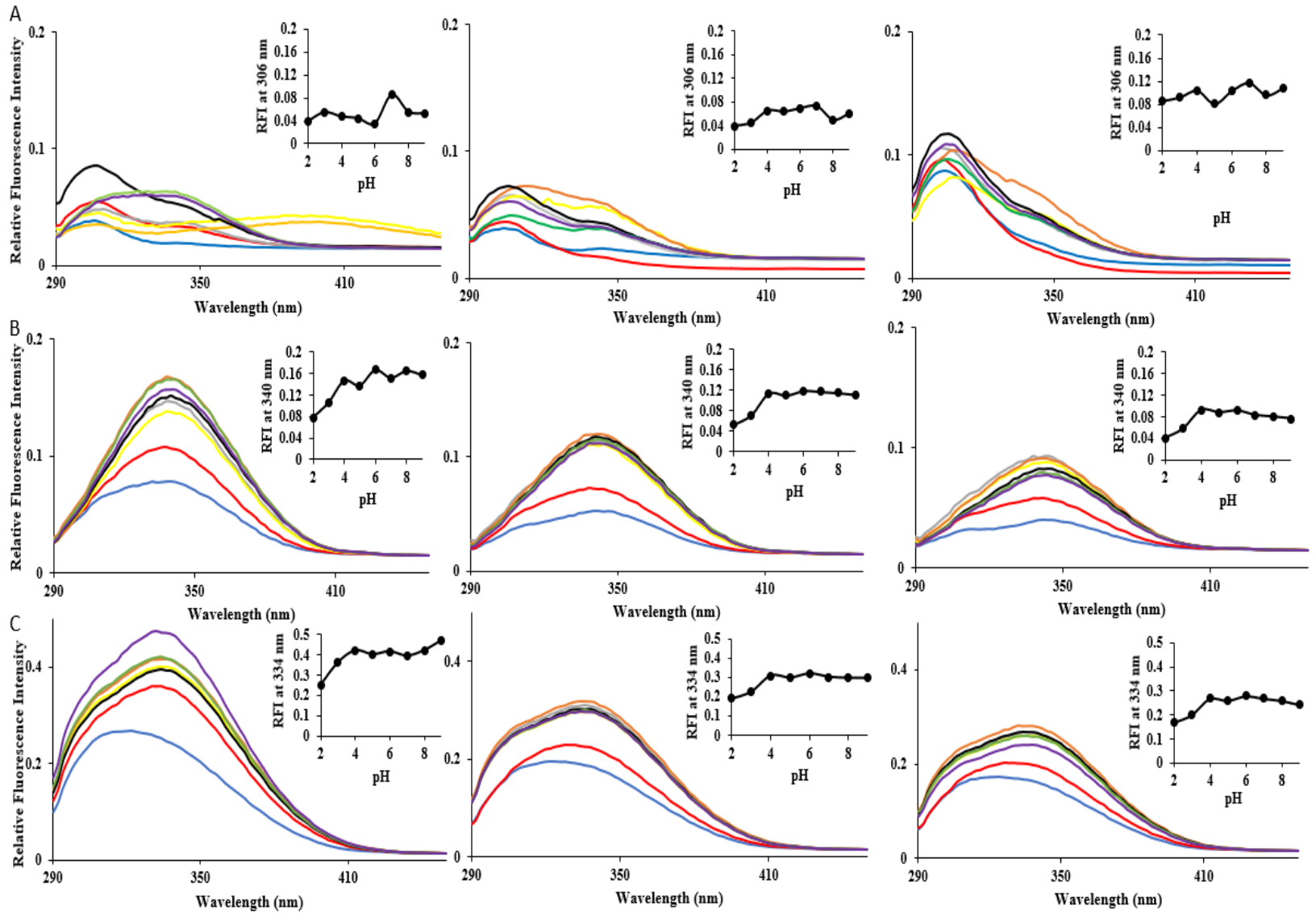

Figure 7. Intrinsic Fluorescence spectra of HSP subunits. Intrinsic Fluorescence (IF) spectra of each HSP subunit: (A) HSPa; (B), HSP 3 , and (C) HSP $\beta$-coh - subjected to a pH range of $2-9$ at $75^{\circ} \mathrm{C}$ (left column), $80^{\circ} \mathrm{C}$ (middle column), and $90^{\circ} \mathrm{C}$ (right column top and middle for $\mathrm{HSPa}$ and $\mathrm{HSP} \beta$, respectively), and $85^{\circ} \mathrm{C}$ (right column bottom for HSP $\beta$ coh) (right column). Inset graphs depict the changes in relative fluorescence intensity at the respective native emission maxima (nm) for each subunit as a function of $\mathrm{pH}$. Color coding is the same for each graph: $\mathrm{pH} 2$ (blue), $\mathrm{pH} 3$ (red), $\mathrm{pH}$ 4 (grey), pH 5 (yellow), pH 6 (orange), pH 7 (black), pH 8 (green), pH 9 (purple).

Anilino naphthalene 8-sulfonate (ANS) is a non-polar dye which is used to probe the presence/extent of solvent-exposed hydrophobic surfaces in protein $(41,50,51)$. This spectrophotometric technique is useful in the study of protein folding under different conditions. The degree of folding, the presence of potential intermediate states, or protein denaturation can be monitored by the exposure of hydrophobic residues on the surface of the protein. Differences in surface hydrophobicity of natural and engineered HSPs appear to be $\mathrm{pH}$ dependent (Fig. 8). ANS binding curves for HSPa and HSP $\beta$ at pH 7 and $75^{\circ} \mathrm{C}$ are comparable (i.e., superimpose). Furthermore, ANS binding for HSPa and $\mathrm{HSP} \beta$ at $\mathrm{pH} 7$ and $90^{\circ} \mathrm{C}$ (i.e., heat shock conditions) exhibit robust congruency. These results suggest that at both physiological $\mathrm{pH}$ and under heat shock, the native tertiary folds of these proteins are not significantly perturbed. ANS for HSP $\beta$-coh at $\mathrm{pH}$ 7, under heat shock (i.e., $85^{\circ} \mathrm{C}$ ) showed a slight increase in RFI as compared to the binding curve at physiological $\mathrm{pH}$ and temperature. For all HSPs at neutral $\mathrm{pH}$ and higher temperatures $\left(75^{\circ} \mathrm{C}, 85^{\circ} \mathrm{C}\right.$, and $\left.90^{\circ} \mathrm{C}\right)$, RFI for ANS binding is lower compared to the RFI at pH 2. 

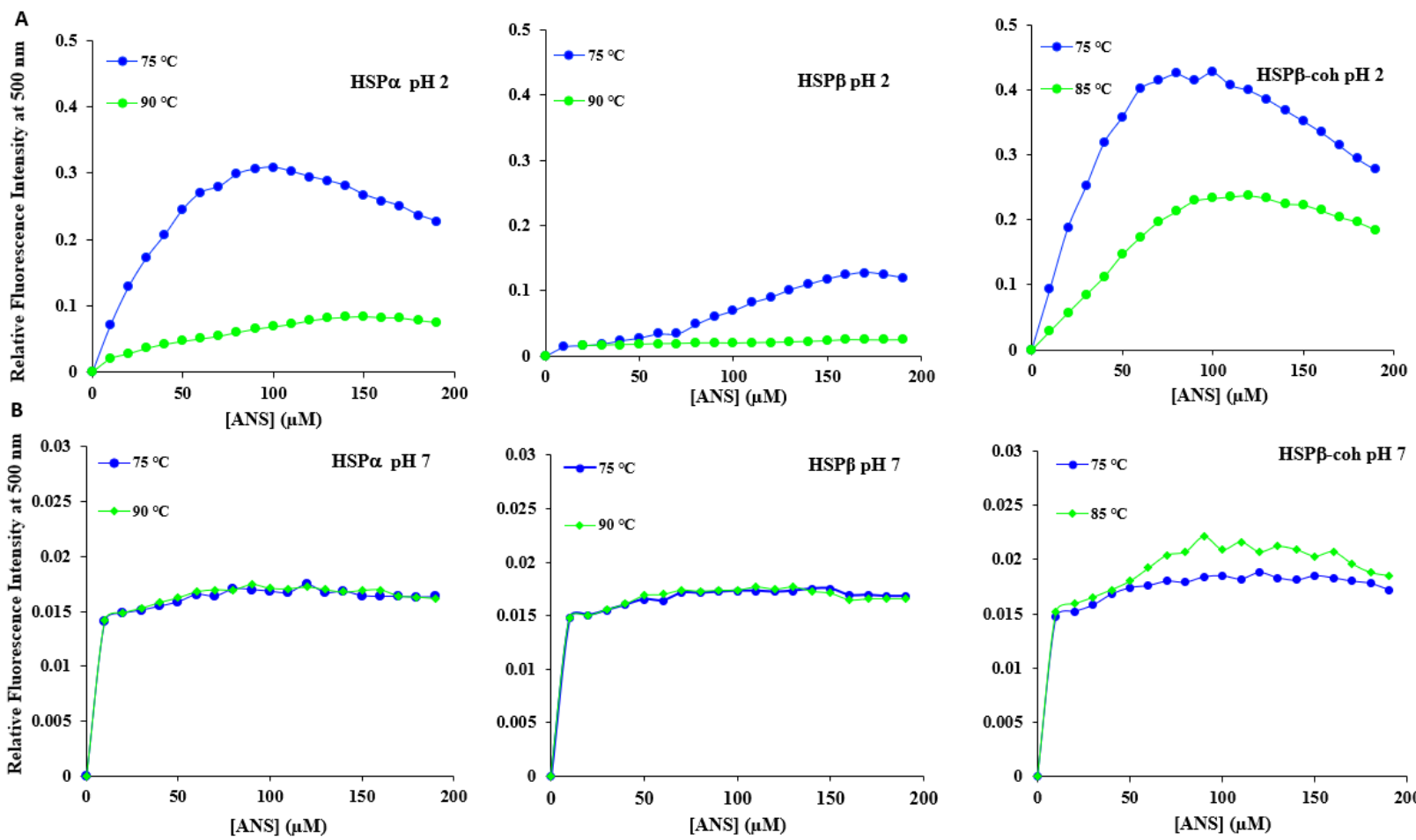

Figure 8. Anilino naphthalene 8-sulfonate (ANS) binding for each HSP subunit. ANS binding curves at: (A) $\mathrm{pH} 2$ for HSPa (left), HSP $\beta$ (middle), and HSP $\beta$-coh (right); and (B) $\mathrm{pH} 7$ for HSPa (left), HSP $\beta$ (middle), and HSP $\beta$-coh (right) - under two temperature conditions $75^{\circ} \mathrm{C}$ (blue) and $85^{\circ}$ (HSP $\beta$-coh, green) or $90^{\circ} \mathrm{C}$ (HSP $\alpha, \mathrm{HSP} \beta$, green).

The hydropathic indices for each protein were calculated by the method of Kite and Doolittle (1982) and the values are averaged at each equivalent position (Fig. S3). Characterization of hydropathy profiles for natural and engineered HSP subunits regions revealed that the natural HSPa and HSP $\beta$ subunits were close mirror images of one another. The mean of the grand average hydropathy score (GRAVY) for natural $\mathrm{HSP} \alpha, \mathrm{HSP} \beta$, and the engineered fusion construct HSP $\beta$-coh were calculated. These GRAVY scores are: 0.00625 for HSPa; -0.2 for HSP $\beta$; and -0.11 for HSP $\beta$-coh, respectively. Although, the hydrophilic profile of these proteins appears conserved across key structural elements, the hydrophobic properties around positions 550-700 of HSP $\beta$-coh was shifted downward (i.e., less hydrophobic) when compared to the natural HSP $\alpha$ and HSP $\beta$ subunits.

\section{Limited trypsin digestion suggests a flexible HSP $\beta$ backbone structure}

Trypsin, a serine protease, which cleaves proteins at the C-terminal end of lysine and arginine residues, is commonly used to assess the backbone flexibility of proteins and to provide low-resolution information regarding structural changes. Time-dependent trypsin digestion was employed to compare the backbone flexibilities between HSP subunits. The percent digestion post-incubation with trypsin for each HSP was measured by densitometric analysis of the 60 and $73 \mathrm{kDa}$ bands in SDS PAGE gels (Fig.S4). The HSP $\beta$-coh subunit is readily degraded by trypsin. Specifically, $87 \%$ of the protein is digested within 2 minutes of trypsin treatment. After 15 minutes of incubation with trypsin $\left(37^{\circ} \mathrm{C}\right)$, the $73 \mathrm{kDa}$ band corresponding to HSP $\beta$-coh fusion protein is completely digested. In comparison, HSP $\beta$ and $\mathrm{HSPa}$ are digested to $75 \%$ and $60 \%$, respectively, after 4 minutes (Fig. 9). 


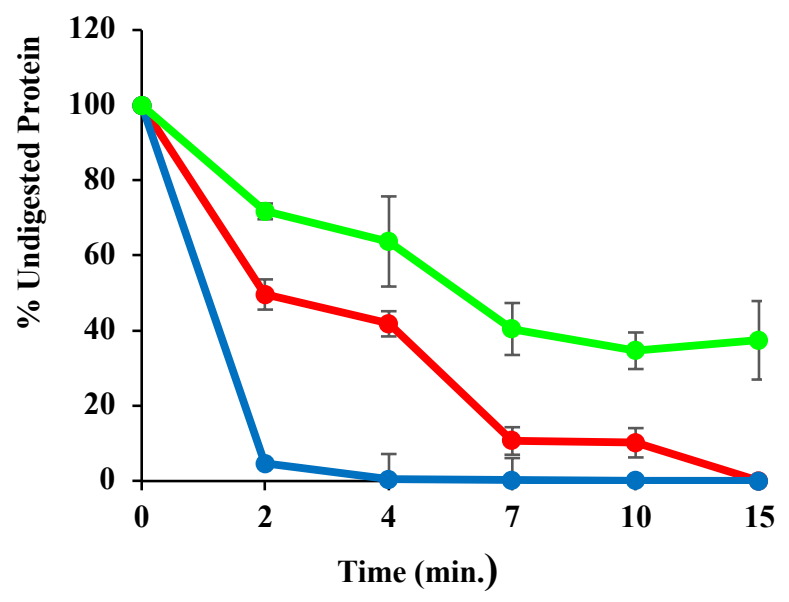

Figure 9. Densitometry for SDS-PAGE gels. depicting the resistance to limited trypsin digestion for HSPa (red), HSP (green), and HSPß-Coh (Blue).

404

405

406

407

408

409

410

411

412

413

414

415

416

417

418

419

420

421

422

423

424

425

426

427

428

429

430

431

432

433

434

435

436

437

438

439

440

441

\section{Discussion}

The structure (and function) of archaeal group II chaperonins has been previously studied $(21,22,52)$. However, neither the staging of 18-mer HSP complex formation, the nature of HSP-client interactions, nor the extent of HSP complex protective action under extremes of $\mathrm{pH}$ and temperature is resolved. Unlike GroEL/ES, which uses a barrel (GroEL)-cap (GroES) system to serve clients, it is proposed that the group II chaperonin complexes (i.e., thermosomes) have both opened and closed states (18). A conformational change in the HSP complex allows client protein interactions within an inner cavity of the thermosome. It is the interaction of the client protein and the interior of the HSP complex that stabilizes the former under conditions of cellular stress (53-56). However, the conformational changes occurring at the level of the HSP subunit driving conformational changes in the complex are not clear. Likewise, the conformational states inducing subunits to form chaperonin complexes remain elusive. Although the upregulation of HSP subunit expression at physiological $\mathrm{pH}$ has been previously shown under heat shock conditions $(55,57,58)$, recent evidence of HSP complex function in protecting client proteins under acidic $(30,59)$ and alkaline $(30)$ conditions suggests that HSPs may be resilient to changes in $\mathrm{pH}$. Neither the extent to which natural or engineered HSPs maintain structural integrity at non-physiological $\mathrm{pH}$ nor the impacts of $\mathrm{pH}$ by temperature on subunit structure has been previously reported. Biophysical characterization of the limits to which HSPs can withstand changes in $\mathrm{pH}$ and temperature is necessary for designing engineered HSP platforms (i.e., MESP) for industrial applications as well as understanding the formation and function of natural HSP complexes (30).

Natural and Engineered HSPs show thermostability. A gross measure of thermal stability can be determined by differential scanning calorimetry (DSC). The DSC output is a melting temperature $\left(T_{\mathrm{m}}\right)$ at which $50 \%$ of the protein population is thermally denatured (40). All three HSP subunits exhibited significant thermostability. This aligns with previous work demonstrating HSP stability under conditions of thermal shock $(18,21)$. $\mathrm{HSP} \alpha$ and $\mathrm{HSP} \beta$ were the most stable with $\mathrm{T}_{\mathrm{m}}$ values at $\sim 94^{\circ} \mathrm{C}$ at neutral $\mathrm{pH}(\mathrm{pH} 7)$. The engineered $\mathrm{HSP} \beta$-coh subunit features a lower $\mathrm{T}_{\mathrm{m}}$ of $\sim 88^{\circ} \mathrm{C}$ at $\mathrm{pH} 7$, which is still high compared to mesophilic proteins (60), and yet significantly lower than the $\mathrm{T}_{\mathrm{m}}$ for the natural HSPa and HSP $\beta$ subunits. Given the similarities between the natural HSP $\beta$ chaperonins and the HSP $\beta$ circular permutant of the HSP $\beta$-coh fusion construct, the lower $T m$ is likely due to thermal sensitivity in the fused cohesin domain. Although $C$. thermocellum is thermophilic $(61,62)$, it is not a hyperthermophile; therefore, cohesin has not evolved at the same temperatures as group II chaperonins of the Sulfolobales (i.e., $\mathrm{HSPa}$ and HSP $\beta$ ). There is a striking drop in $\mathrm{T}_{\mathrm{m}}$ with decrease in $\mathrm{pH}$. For all three HSP subunits, $\mathrm{Tm}_{\mathrm{m}}$ drops $\sim 25^{\circ} \mathrm{C}-30^{\circ} \mathrm{C}$. This indicates a strong $\mathrm{pH}$ by temperature impact on the thermostability of these chaperonin subunits. To better understand the nature of this sensitivity to $\mathrm{pH}$ intrinsic fluorescence (IF), trypsin digestion, Anilino naphthalene 8-sulfonate (ANS), and circular dichroism (CD) were employed. 
Integrity of HSP tertiary structure shows $\mathbf{p H}$ dependency. To further explore $\mathrm{pH}$ by temperature effects on HSP structural stability, intrinsic tryptophan (Trp) and tyrosine (Tyr) fluorescence was used. Since the HSPa subunit does not contain Trp residues, IF for HSPa relied on Tyr-based fluorescence. $\mathrm{IF}_{\mathrm{Tyr}}$ for HSPa shows a peak at $306 \mathrm{~nm}$ with the highest relative fluorescence intensity (RFI) at $\mathrm{pH} 7$ under all temperature conditions. Although the $\mathrm{IF}_{\mathrm{Tyr}}$ emission peak does not significantly shift upon altering $\mathrm{pH}$, lower $\mathrm{pH}$ conditions result in decreased $\mathrm{RFI}$ compared to $\mathrm{pH} 7$ across all temperature conditions indicating the possibility of supercoiling which was substantiated by the 222/208 nm ratio results for $\mathrm{HSP} \alpha$ at $\mathrm{pH}$ 2. What is clear is that $\mathrm{pH}$ does impact the native tertiary fold. In HSP $\beta$, IFTrp shows an emission maximum at $340 \mathrm{~nm}$, indicating partial exposure of tryptophan residues.

452

453

454

455

456

457

458

459

460

461

462

463

464

465

466

467

468

469

470

471

472

473

474

475

476

477
Multiple trials (including data from Fig. 7) suggest that low $\mathrm{pH}$ environments do not result in notable shifts in the emission maxima for HSPa and HSP $\beta$ across all temperature conditions. However, under all temperature conditions, decreases in RFI are observed most prominently at lower pH conditions $(\mathrm{pH} 2$ and 3). HSP $\beta$-coh exhibits a broader IF spectrum, possibly due to the additional tyrosine residues in cohesin that augments those of HSP $\beta$. Likewise, since the HSP $\beta$-coh is comprised of a circular permutant of HSP $\beta$, the location of tryptophan residues is altered. Together, this likely account for the peak at $\sim 334 \mathrm{~nm}$ and the less prominent shoulder at $\sim 306 \mathrm{~nm}$. A notable blue-shift is observed at $\mathrm{pH} 2$ and 3 for $\mathrm{HSP} \beta$-coh at all temperatures examined, suggesting that ultra-low $\mathrm{pH}$ conditions cause this fusion protein to undergo changes in tertiary structure, which may indicate an unfolded intermediate state (Fig. 7, panel C).

DSC indicates a global breakdown in thermostability of HSPs under low pH conditions while IF indicates more subtle changes in HSP subunit conformation in $\mathrm{pH}$ by temperature interactions. To further investigate the effects of $\mathrm{pH}$ (and temperature) on tertiary structure, Anilino naphthalene 8sulfonate (ANS) and trypsin digestion assays were conducted. ANS binding assays clearly demonstrate $\mathrm{pH}$ by temperature perturbations in $\mathrm{HSP}$ tertiary structure. At $\mathrm{pH}$ 7, ANS shows negligible changes in emissions from non-polar surfaces of $\mathrm{HSP} \alpha$ and $\mathrm{HSP} \beta$ at $75^{\circ} \mathrm{C}$ (physiological) and $90^{\circ} \mathrm{C}$ (heat shock). This result reflects that no significant changes to the solvent exposed hydrophobic surface(s) have been induced as a consequence of heat shock. At pH 7, HSP $\beta$-coh shows minor increases in RFI with mild heat shock $\left(85^{\circ} \mathrm{C}\right)$ the $75^{\circ} \mathrm{C}$ condition. (Again, the increase in RFI may be a result of ANS binding to the cohesion domain of HSP $\beta$-coh). However, when the environment is adjusted to $\mathrm{pH} 2$, perturbations in tertiary structure are observed. Specifically, significant increases in ANS RFI (i.e., 10-fold ${ }^{+}$) are observed for all three HSP subunits. This suggests that low $\mathrm{pH}$ conditions induce conformational changes in these chaperonins exposing non-polar surfaces to ANS binding. Since hydropathy plots indicate that HSP $\beta$-coh features more hydrophobic regions than $\mathrm{HSP \alpha}$ or HSP $\beta$, increased ANS RFI amplitudes for HSP $\beta$-coh is reasonable. Limited trypsin digest (LTD) is another method for assessing protein backbone stability/flexibility. Acknowledging that HSP $\beta$-coh has more trypsin cleavage sites than HSPa or HSP 3 : 82,72 , and 75 , respectively (63). HSP $\beta$ has the highest backbone stability and therefore the least flexible structure of the three subunits. HSPa was slightly more susceptible to cleavage than HSP $\beta$. The backbone structure of HSP $\beta$-coh was observed to have the highest flexibility with the most susceptibility to cleavage, likely due to the addition of the cohesion moiety (see Fig. 7). Although increased thermostability and increased flexibility can coincide, thermophilic proteins have been shown to retain less flexibility than comparable mesophiles $(64,65)$. Although LTD can only be done at neutral $\mathrm{pH}$ (to avoid disrupting enzyme activity), these data support results from IF, DSC, and ANS, suggesting that HSP $\beta$ is overall the most stable subunit under the $\mathrm{pH}$ and temperature conditions tested. This may be due to a more compact three-dimensional structure.

HSP secondary structure exhibits resilience to shifts in $\mathrm{pH}$. Although DSC, IF, and ANS data suggest significant $\mathrm{pH}$ by temperature effects on the structure of HSPs, these methods provide data on gross protein structural changes. It is critical to know whether the conformational shifts observed using these biophysical and biochemical techniques predominantly represent perturbations to tertiary structure or whether secondary structural elements are also impacted by $\mathrm{pH}$. To explore the resilience 
of HSP secondary structure to changes in $\mathrm{pH}$ and temperature, circular dichroism (CD) was employed. All three HSPs tested show resiliency in the integrity of secondary structural elements over a range of temperatures $\left(25^{\circ} \mathrm{C}-85^{\circ} \mathrm{C}\right)$ as demonstrated by far-UV CD. Taken together, $\mathrm{CD}$ and $\mathrm{DSC}$ data suggest that at physiological $\mathrm{pH}$, which represents the $\mathrm{pH}$ of the intracellular environment of the Sulfolobus cell from which these subunits were derived, thermal stability is robust.

Comparisons of far-UV spectral data using both $[\theta] 222 /[\theta] 208$ ratio and weighted spectral differences (WSD) indicate that secondary structural elements are stable across temperature ranges at neutral $\mathrm{pH}$. Secondary structure also appears to be more resilient at $\mathrm{pH} 4$ than $\mathrm{pH} 2$ for all three subunits, with $\mathrm{HSPa}$, exhibiting the greatest sensitivity to $\mathrm{pH}$. The apparent stability of secondary structural elements at low $\mathrm{pH}$ with global collapse at ultra-low $\mathrm{pH}$ (e.g., $\mathrm{pH} 2$ ) suggests that HSP tertiary structure is perturbed while preserving secondary structure under mildly acid $(\mathrm{pH} 3-6)$ conditions. Acid tolerance of secondary structure would allow for protein re-folding and preservation of function, while denaturation would likely occur at ultra-low $\mathrm{pH}$. Whether the conformational shifts shown under mildly acid conditions represent intermediate conformational states associated with chaperonin-client protein interactions or HSP complex formation is not known. However, the presence of coiled-coil signatures in $\mathrm{CD}$ data suggest adaptation of a more compact structure at low $\mathrm{pH}$.

HSP gel data and structural models indicate $\mathrm{pH}$ by temperature conformational shifts. Protein gel electrophoresis that does not include use of a denaturant (i.e., SDS) may be described as Native PAGE (66). Native PAGE for purified HSPs at physiological pH reveals several bands including a high molecular weight band at $\sim 1200 \mathrm{kDa}$ likely representing the 18-mer complex. Depending upon whether ATP and $\mathrm{MgCl}_{2}$ is added to solution bands form with varying densities at molecular weights consistent with dimer, trimer, and nanomer (i.e., ring) formation. When HSP samples are subjected to ultra-low $\mathrm{pH}$ (i.e., $\mathrm{pH}$ 2) prior to conducting Native PAGE, gels resolve bands in the trimer and tetramer range for the $\sim 60 \mathrm{kDA}$ subunits. Taken with the CD data, these data raise the possibility that HSP conformational transitions (i.e., formation of coiled coils) may be essential for HSP complex formation. Specifically, interactions between a-helices on separate HSP molecules may comprise a fraction of the coiled-coil population. Movement between structural domains (i.e., apical, intermediate, equatorial) was observed in molecular dynamics simulations of $\mathrm{HSP} \alpha$ and $\mathrm{HSP} \beta$ at $\mathrm{pH} 2$ and $\mathrm{pH} 7$ (70). Whether these shifts in tertiary structure are conformational intermediates required for HSP complex formation or HSP-client protein interaction requires further investigation.

\section{Experimental Procedures}

\section{Expression and Purification of Natural and Engineered HSP proteins}

$\mathrm{HSP} \alpha, \mathrm{HSP} \beta$, and engineered HSP $\beta$-cohesin fusion proteins were purified as previously described methods with some modifications $(28,36)$. Escherichia coli expressing natural (HSPa, HSP $\beta$ and engineered (HSP $\beta$-coh) subunits from $S$. shibatae were harvested by centrifugation at $7000 \mathrm{rpm}$ for $15 \mathrm{~min}$ at $4^{\circ} \mathrm{C}$ (Sorvall RC- 5 ) and cells were resuspended in buffer (50mM Tris- HCl, $1 \mathrm{mM}$ EDTA and $\mathrm{pH} 7.5$ ), sonicated for 25 cycles (10 sec on/10 sec off) using SONIFIER 250, duty cycle 20\%, and centrifuged at $16,000 \mathrm{xg}$ for $20 \mathrm{~min}$ to separate supernatant from cellular debris. The supernatant extract was heated to $80{ }^{\circ} \mathrm{C}\left(\mathrm{HSP} \alpha\right.$ and $\mathrm{HSP} \beta$ ) or $70{ }^{\circ} \mathrm{C}$ (engineered HSP $\beta$-coh) for 30 min and centrifuged at $18,500 \mathrm{xg}$ for $30 \mathrm{~min}$ to remove non-heat tolerant proteins. The supernatants were further purified to homogeneity by anion exchange chromatography (Bio-Rad Q Sepharose Column, USA), using a $150 \mathrm{mM}$ to $1 \mathrm{M} \mathrm{NaCl}$ gradient for $30 \mathrm{~min}$ at $3 \mathrm{~mL} / \mathrm{min}$. The eluted proteins were collected and concentrated using a $30 \mathrm{kDa}$ Amicon Ultra-15 centrifugal filter (EMD Millipore) and dialyzed overnight with $10 \mathrm{kDa}$ SnakeSkinTM dialysis tubing (Thermo Scientific) at $4^{\circ} \mathrm{C}$ in $20 \mathrm{mM}$ Tris- $\mathrm{HCl}(\mathrm{pH}$ 8.0). All purified proteins were stored at $-80^{\circ} \mathrm{C}$ for further analysis. The eluted fractions of protein concentrations were determined by Bradford protein estimation with BSA standards and proteins were analyzed by using SDS PAGE. 


\section{Gel Electrophoresis (SDS-PAGE)}

545
Proteins were resolved using $12 \%$ acrylamide resolving gel (Sambrook et al., 1989). Protein samples were mixed with SDS sample buffer (0.25\% Coomassie Brilliant blue (R250), 2\% SDS, $10 \%$ glycerol $(\mathrm{v} / \mathrm{v}), 100 \mathrm{mM}$ tris, and $1 \% \beta$-mercaptoethanol) at a ratio of $4: 1$ and boiled for 5 minutes. The boiled samples were loaded in respective wells and prestained protein molecular weight markers were also loaded (ThermoFisher Scientific, Cat.26620). The electrophoresis was performed at 150 volts for one hour using the Bio-Rad Mini protein electrophoresis system (Biorad, U.S.A). Gels were stained with Coomassie Brilliant Blue R-250 and destained with a mixture of methanol, water, and acetic acid $(4: 4: 1)$.

\section{Silver staining of polyacrylamide gels}

After electrophoresis, gels were incubated for 10 minutes in fixing solution ( $40 \%(\mathrm{v} / \mathrm{v})$ methanol, $13.5 \%$ $(\mathrm{v} / \mathrm{v})$ formalin), resulting in precipitation of the proteins and diffusion of SDS. Subsequently, gels were placed into incubation solution $\left(0.01 \mathrm{~g} \mathrm{Na}_{2} \mathrm{~S}_{2} \mathrm{O}_{3}\right)$ for 1 minute to oxidize the proteins. Gels were then washed with water three times for 5 minutes and transferred into silver solution ( $0.05 \mathrm{~g}$ silver nitrate) for another 10 minutes. Thereafter, proteins were visualized by replacement of the silver solution with developing solution ( $1.5 \mathrm{~g} \mathrm{Na}_{2} \mathrm{CO}_{3}, 25 \mu \mathrm{l}$ formalin, $50 \mu \mathrm{l}$ of $0.02 \% \mathrm{Na}_{2} \mathrm{~S}_{2} \mathrm{O}_{3}$ ). The sodium carbonate of the latter solution reduces the silver nitrate attached to the proteins and thus the proteins adopt a brown color. As soon as the desired staining intensity was reached, the reaction was stopped by addition of citric acid solution (2.3M), which was exchanged with water after 10 minutes.

\section{Circular dichroism spectroscopy}

Far-UV circular dichroism (Far-UV CD) experiments were performed on a Jasco-1500 spectrophotometer. Thermal denaturation experiments were performed at temperatures ranging from $25-90^{\circ} \mathrm{C}$ at $5^{\circ} \mathrm{C}$ increments using protein concentrations of $0.3 \mathrm{mg} / \mathrm{mL}$ in $10 \mathrm{mM}$ sodium phosphate buffer containing $10 \mathrm{mM} \mathrm{NaCl}$ with pH adjusted to 2, 4 and 7. The data was smoothened via application of the Savitzky-Golay algorithm.

The Weighted Spectral Difference (WSD) for each temperature and $\mathrm{pH}$ condition was calculated according to Dinh et al., 2014 (43). The equation used to find the magnitude-weighted Euclidean distance between spectra was:

where $n$ is the number of wavelengths measured within the spectral range, $y_{A i}$ is the $i^{\text {th }}$ sample of the reference spectra, $y_{A i}$ is the ith sample of the sample spectra, and $\left|y_{A}\right|_{\text {avg }}$ is the average absolute molar ellipticity of the reference sample. The smoothed spectra corresponding to $\mathrm{pH}=7$ and $\mathrm{T}=75^{\circ} \mathrm{C}$ was used as the reference spectra for each protein. The range of wavelengths 200 to $250 \mathrm{~nm}$ were utilized in this calculation. All WSD calculations were completed in R (R_CS). 
All intrinsic fluorescence measurements were performed on a Jasco-1500 spectrophotometer using a $10 \mathrm{~mm}$ quartz cuvette with protein concentrations of $0.2 \mathrm{mg} / \mathrm{mL}$ in $10 \mathrm{mM}$ sodium phosphate buffer containing $100 \mathrm{mM} \mathrm{NaCl}$ with $\mathrm{pH}$ ranging from 2-9 at $\mathrm{pH}$ increments of 1 and held at temperatures $75^{\circ} \mathrm{C}, 80^{\circ} \mathrm{C}, 85^{\circ} \mathrm{C}$, and $90^{\circ} \mathrm{C}$. Protein samples were excited at a wavelength of $280 \mathrm{~nm}$ and the emission spectra was recorded from $290 \mathrm{~nm}$ to $450 \mathrm{~nm}$. ANS binding assays were performed using protein concentrations of $0.2 \mathrm{mg} / \mathrm{ml}$. Stock ANS was made such that $2 \mu \mathrm{L}$ titrations into the protein sample would increase the ANS concentration by $10 \mu \mathrm{M}$ increments. Fluorescence measurements were made after each titration until saturation was reached. Samples were excited at $380 \mathrm{~nm}$ and emission was recorded at $500 \mathrm{~nm}$. Measurements were recorded under variable $\mathrm{pH}$ buffer conditions $(\mathrm{pH} 2$ and 7) and variable temperature conditions $\left(75^{\circ} \mathrm{C}, 85^{\circ} \mathrm{C}\right.$, and $\left.90^{\circ} \mathrm{C}\right)$

\section{Differential Scanning Calorimetry (DSC)}

All protein samples were prepared at a concentration of $0.5 \mathrm{mg} / \mathrm{ml}$ in $10 \mathrm{mM}$ phosphate buffer. A NDSC III Differential Scanning calorimeter was used to determine the melting temperatures. Prior to loading, all the protein samples were subjected to degassing at $25^{\circ} \mathrm{C}$ for 15 minutes. Scans were performed from 25 to $110^{\circ} \mathrm{C}$ with a $1{ }^{\circ} \mathrm{C} / \mathrm{min}$ ramping temperature and at variable $\mathrm{pH}$ solutions $(\mathrm{pH} 2$, 4 , and 7). To obtain a stable baseline, buffer runs were conducted before running the protein scans. Blank subtraction was performed, and data obtained was processed using CpCalc Version 2.2.0.10 software provided by the manufacturer.

\section{Limited Trypsin Digestion}

Limited trypsin digestion experiments were performed on all HSP subunits. The initial reaction mixture included $0.2 \mathrm{mg} / \mathrm{ml}$ of protein and $0.000781 \mathrm{mg} / \mathrm{ml}$ of trypsin in $10 \mathrm{mM}$ sodium phosphate buffer at $\mathrm{pH}$ 7.2. Trypsin digestion was carried out at $37^{\circ} \mathrm{C}$ and a portion of the reaction mixture was removed, at specified time intervals over 15 minutes. The reaction was arrested by precipitation using trichloroacetic acid. The reaction products were analyzed by $15 \%$ SDS-PAGE and the gels were stained using Coomassie Brilliant Blue (Sigma Aldrich). The band intensities for SDS-PAGE were estimated to determine the percentage of proteolytic digestion using UN-SCAN-IT densiometric software. The intensity of HSP samples not subjected to proteolytic digestion was used as the control representing $100 \%$ protection from enzymatic degradation.

\section{Structural Modeling}

The FASTA sequences of the Heat Shock Proteins (HSPa and HSP $\beta$ ) from S. shibatae, were uploaded to the SWISS Model (67). Sequences with similarity of $60 \%$ or more were chosen for the templates of HSP $\alpha$ and HSP $\beta$, to generate 3-dimensional models in PDB format for both proteins. After that, the chosen models were subjected to energy minimization and RMSD Calculations using Swiss PDB Deep Viewer to select the best model for each protein (68). Further, HSPa and HSP $\beta$ were subjected to scan using EMBL-EBI InterPro to visualize the domains (34). The highly conserved domains among all the sub-units, including HSP $\beta$-coh, were marked using ESPript (69). The Secondary Structures for the HSPs were visualized using the Swiss PDB Deep Viewer (68). NsitePred webserver was used to determine the possible ADP/ATP exchange sites (37). Finally, PyMOL (The PyMOL Molecular Graphics System, Version 2.0 Schrödinger, LLC.) was used to visualize and label the three functional domains (Apical, Intermediate, and Equatorial), the conserved domains, Secondary Structure (Alpha Helices, Beta Sheets and Turns), the hydrophobic residues, ATP sites, and the N or C Terminus in the 3-Dimensional structure of the proteins. 
631

632

633

634

635

636

637

638

639

640

641

642

643

644

645

646

647

648

649

650

651

652

653

654

655

656

657

658

659

660

661

662

663

664

665

666

667

668

669

670

671

672

673

674

675

676

677

678

679

680

681

682

683

\section{Conclusions}

Detailed biophysical analysis of natural chaperonins (HSP $\alpha$ and $\mathrm{HSP} \beta)$ and an engineered HSP $\beta$-coh construct indicate that, despite the high thermostability of all three subunits, the tertiary structures of all three HSPs are affected by $\mathrm{pH}$. Other work by our lab has indicated that HSP complexes may be resilient to low pH conditions (71); however, biophysical analyses indicate that the tertiary structures of these HSPs are sensitive to changes in $\mathrm{pH}$. Nonetheless, secondary structural elements of these HSPs do show some resilience to acid conditions suggesting that function may be retained after $\mathrm{pH}$ challenge. A molecular dynamics simulation study (70) supports this suggestion. Additional studies are required to demonstrate retention of $\mathrm{HSP}$ function after $\mathrm{pH}$ challenge. This is the subject of ongoing work in the lab. More work is required to explore conformational shifts in these HSP subunits to determine if intermediate states induced by $\mathrm{pH}$ by temperature challenges are important for HSP complex formation, HSP-client protein interactions, or switching between opened and closed states in a functional thermosome (i.e., 18-mer HSP complex). Detailed analyses of structural changes including potential intermediates to key conformational changes are required for both natural and engineered constructs to direct development of artificial HSP platforms (i.e., MESPs).

\section{Acknowledgements}

This work was supported by two awards from the U.S. National Science Foundation: a NSF MCB grant (award no. 1818346; PI-Ceballos) and a NSF INFEWS grant (award no. 1856091; PI-Ceballos). A University of Arkansas Chancellor's Innovation and Commercialization award supported the participation of MF and SB. The authors would like to thank Dr. Mary Cloninger of Montana State University and Dr. J.B. Alexander "Sandy" Ross of the University of Montana for comments and suggestions during the preparation of this manuscript. 


\section{References}

685

686

687

688

689

690

691

692

693

694

695

696

697

698

699

700

701

702

703

704

705

706

707

708

709

710

711

712

713

714

715

716

717

718

719

720

721

722

723

724

725

726

727

728

729
1. Lopez, T., Dalton, K., and Frydman, J. (2015) The mechanism and function of group II chaperonins. Journal of molecular biology 427, 2919-2930

2. Saibil, H. (2013) Chaperone machines for protein folding, unfolding and disaggregation. Nature reviews Molecular cell biology 14, 630-642

3. Skjærven, L., Cuellar, J., Martinez, A., and Valpuesta, J. M. (2015) Dynamics, flexibility, and allostery in molecular chaperonins. FEBS letters 589, 2522-2532

4. Chaston, J. J., Smits, C., Aragão, D., Wong, A. S., Ahsan, B., Sandin, S., Molugu, S. K., Molugu, S. K., Bernal, R. A., and Stock, D. (2016) Structural and functional insights into the evolution and stress adaptation of type II chaperonins. Structure 24, 364-374

5. Gupta, A. J., Haldar, S., Miličić, G., Hartl, F. U., and Hayer-Hartl, M. (2014) Active cage mechanism of chaperonin-assisted protein folding demonstrated at single-molecule level. Journal of molecular biology 426, 2739-2754

6. Zhang, Z., Eloge, J., and Florián, J. (2014) Quantum mechanical analysis of nonenzymatic nucleotidyl transfer reactions: kinetic and thermodynamic effects of $\beta-\gamma$ bridging groups of dNTP substrates. Biochemistry 53, 4180-4191

7. Lin, Z., Madan, D., and Rye, H. S. (2008) GroEL stimulates protein folding through forced unfolding. Nature structural \& molecular biology 15, 303

8. Lin, Z., Puchalla, J., Shoup, D., and Rye, H. S. (2013) Repetitive protein unfolding by the trans ring of the GroEL-GroES chaperonin complex stimulates folding. Journal of Biological Chemistry 288, 30944-30955

9. Sharma, S., Chakraborty, K., Müller, B. K., Astola, N., Tang, Y.-C., Lamb, D. C., HayerHartl, M., and Hartl, F. U. (2008) Monitoring protein conformation along the pathway of chaperonin-assisted folding. Cell 133, 142-153

10. Niwa, T., Fujiwara, K., and Taguchi, H. (2016) Identification of novel in vivo obligate GroEL/ES substrates based on data from a cell-free proteomics approach. FEBS letters 590, 251-257

11. Braig, K., Otwinowski, Z., Hegde, R., Boisvert, D. C., Joachimiak, A., Horwich, A. L., and Sigler, P. B. (1994) The crystal structure of the bacterial chaperonln GroEL at $2.8 \AA$. Nature 371, 578-586

12. Weiss, C., Jebara, F., Nisemblat, S., and Azem, A. (2016) Dynamic complexes in the chaperonin-mediated protein folding cycle. Frontiers in molecular biosciences 3, 80

13. Cong, Y., Schröder, G. F., Meyer, A. S., Jakana, J., Ma, B., Dougherty, M. T., Schmid, M. F., Reissmann, S., Levitt, M., and Ludtke, S. L. (2012) Symmetry-free cryo-EM structures of the chaperonin TRiC along its ATPase-driven conformational cycle. The EMBO journal 31, 720-730

14. Horwich, A. L., Fenton, W. A., Chapman, E., and Farr, G. W. (2007) Two families of chaperonin: physiology and mechanism. Annu. Rev. Cell Dev. Biol. 23, 115-145

15. Sigler, P. B., and Horwich, A. L. (1995) Unliganded GroEL at 2.8 Å: structure and functional implications. Philosophical Transactions of the Royal Society of London. Series B: Biological Sciences 348, 113-119

16. Boisvert, D. C., Wang, J., Otwinowski, Z., Norwich, A. L., and Sigler, P. B. (1996) The $2.4 \AA$ crystal structure of the bacterial chaperonin GroEL complexed with ATP $\gamma$ S. Nature structural biology 3, 170-177 
17. Trent, J. D., Nimmesgern, E., Wall, J. S., Hartl, F.-U., and Horwich, A. L. (1991) A molecular chaperone from a thermophilic archaebacterium is related to the eukaryotic protein t-complex polypeptide-1. Nature 354, 490-493

18. Trent, J., Osipiuk, J., and Pinkau, T. (1990) Acquired thermotolerance and heat shock in the extremely thermophilic archaebacterium Sulfolobus sp. strain B12. Journal of bacteriology 172, 1478-1484

19. Quehenberger, J., Shen, L., Albers, S.-V., Siebers, B., and Spadiut, O. (2017)

20. Jonuscheit, M., Martusewitsch, E., Stedman, K. M., and Schleper, C. (2003) A reporter gene system for the hyperthermophilic archaeon Sulfolobus solfataricus based on a selectable and integrative shuttle vector. Molecular microbiology 48, 1241-1252

21. Kagawa, H. K., Yaoi, T., Brocchieri, L., McMillan, R. A., Alton, T., and Trent, J. D. (2003) The composition, structure and stability of a group II chaperonin are temperature regulated in a hyperthermophilic archaeon. Molecular microbiology 48, 143-156

22. Kagawa, H. K., Osipiuk, J., Maltsev, N., Overbeek, R., Quaite-Randall, E., Joachimiak, A., and Trent, J. D. (1995) The $60 \mathrm{kDa}$ Heat Shock Proteins in the Hyperthermophilic ArchaeonSulfolobus shibatae. Journal of molecular biology 253, 712-725

23. Kapatai, G., Large, A., Benesch, J. L., Robinson, C. V., Carrascosa, J. L., Valpuesta, J. M., Gowrinathan, P., and Lund, P. A. (2006) All three chaperonin genes in the archaeon Haloferax volcanii are individually dispensable. Molecular microbiology 61, 1583-1597

24. Knapp, S., Schmidt-Krey, I., Hebert, H., Bergman, T., Jörnvall, H., and Ladenstein, R. (1994) The molecular chaperonin TF55 from the thermophilic archaeon Sulfolobus solfataricus: a biochemical and structural characterization. Journal of molecular biology 242, 397-407

25. Phipps, B. M., Hoffmann, A., Stetter, K. O., and Baumeister, W. (1991) A novel ATPase complex selectively accumulated upon heat shock is a major cellular component of thermophilic archaebacteria. The EMBO journal 10, 1711-1722

26. Bigotti, M. G., and Clarke, A. R. (2008) Chaperonins: The hunt for the Group II mechanism. Archives of biochemistry and biophysics 474, 331-339

27. Spiess, C., Meyer, A. S., Reissmann, S., and Frydman, J. (2004) Mechanism of the eukaryotic chaperonin: protein folding in the chamber of secrets. Trends in cell biology 14, 598-604

28. Mitsuzawa, S., Kagawa, H., Li, Y., Chan, S. L., Paavola, C. D., and Trent, J. D. (2009) The rosettazyme: a synthetic cellulosome. Journal of biotechnology 143, 139-144

29. Ceballos, R. M., Marceau, C. D., Marceau, J. O., Morris, S., Clore, A. J., and Stedman, K. M. (2012) Differential virus host-ranges of the Fuselloviridae of hyperthermophilic Archaea: implications for evolution in extreme environments. Frontiers in Microbiology 3, 295

30. Ceballos, R. M., Ceballos Jr, R. M., Rani, A., Morales, C. T., and Batchenkova, N. A. (2014) Improved Hydrolysis of Pretreated Lignocellulosic Biomass using Mobile Enzyme Sequestration Platforms. Recent Advances in Energy, Environment, and Materials, 47-54

31. Wang, J., Enriquez, A. S., Li, J., Rodriguez, A., Holguin, B., Von Salzen, D., Bhatt, J. M., and Bernal, R. A. (2019) MitCHAP-60 and hereditary spastic paraplegia SPG-13 
803

804

805

806

807

808

809

810

811

812

813

814

815

816

817

818

819

820

arise from an inactive hsp60 chaperonin that fails to fold the ATP synthase $\beta$-subunit. Scientific reports $9,1-13$

32. MOLL, R., and SCHÄFER, G. (1991) Purification and characterisation of an archaebacterial succinate dehydrogenase complex from the plasma membrane of the thermoacidophile Sulfolobus acidocaldarius. European journal of biochemistry 201, 593600

33. Schocke, L., Bräsen, C., and Siebers, B. (2019) Thermoacidophilic Sulfolobus species as source for extremozymes and as novel archaeal platform organisms. Current opinion in biotechnology 59, 71-77

34. Gasteiger, E., Hoogland, C., Gattiker, A., Wilkins, M. R., Appel, R. D., and Bairoch, A. (2005) Protein identification and analysis tools on the ExPASy server. The proteomics protocols handbook, 571-607

35. DeLano, W. L. (2002) Pymol: An open-source molecular graphics tool. CCP4 Newsletter on protein crystallography $\mathbf{4 0}, 82-92$

36. Paavola, C., Chan, S., Li, Y., Mazzarella, K., McMillan, R., and Trent, J. (2006) A versatile platform for nanotechnology based on circular permutation of a chaperonin protein. Nanotechnology 17, 1171

37. Ranson, N. A., Farr, G. W., Roseman, A. M., Gowen, B., Fenton, W. A., Horwich, A. L., and Saibil, H. R. (2001) ATP-bound states of GroEL captured by cryo-electron microscopy. Cell 107, 869-879

38. Thompson, J. D., Gibson, T. J., and Higgins, D. G. (2003) Multiple sequence alignment using ClustalW and ClustalX. Current protocols in bioinformatics, 2.3. 1-2.3. 22

39. Gouet, P., Robert, X., and Courcelle, E. (2003) ESPript/ENDscript: extracting and rendering sequence and $3 \mathrm{D}$ information from atomic structures of proteins. Nucleic acids research $\mathbf{3 1}, 3320-3323$

40. Gill, P., Moghadam, T. T., and Ranjbar, B. (2010) Differential scanning calorimetry techniques: applications in biology and nanoscience. Journal of biomolecular techniques: JBT 21, 167

41. Cardamone, M., and Puri, N. (1992) Spectrofluorimetric assessment of the surface hydrophobicity of proteins. Biochemical Journal 282, 589-593

42. Whitmore, L., and Wallace, B. A. (2008) Protein secondary structure analyses from circular dichroism spectroscopy: methods and reference databases. Biopolymers: Original Research on Biomolecules 89, 392-400

43. Dinh, N. N., Winn, B. C., Arthur, K. K., and Gabrielson, J. P. (2014) Quantitative spectral comparison by weighted spectral difference for protein higher order structure confirmation. Analytical biochemistry 464, 60-62

44. Crooks, R. O., Rao, T., and Mason, J. M. (2011) Truncation, randomization, and selection: generation of a reduced length c-Jun antagonist that retains high interaction stability. Journal of Biological Chemistry 286, 29470-29479

45. Lau, S., Taneja, A., and Hodges, R. (1984) Synthesis of a model protein of defined secondary and quaternary structure. Effect of chain length on the stabilization and formation of two-stranded alpha-helical coiled-coils. Journal of Biological Chemistry 259, 13253-13261

46. Kwok, S. C., and Hodges, R. S. (2004) Stabilizing and destabilizing clusters in the hydrophobic core of long two-stranded $\alpha$-helical coiled-coils. Journal of Biological Chemistry 279, 21576-21588 
821 47. Royer, C. A. (1995) Fluorescence spectroscopy. in Protein stability and folding,

48. Eftink, M. R. (2002) Intrinsic fluorescence of proteins. in Topics in fluorescence spectroscopy, Springer. pp 1-15

49. Royer, C. A. (1995) Approaches to teaching fluorescence spectroscopy. Biophysical journal 68, 1191

50. Gasymov, O. K., and Glasgow, B. J. (2007) ANS fluorescence: potential to augment the identification of the external binding sites of proteins. Biochimica et Biophysica Acta (BBA)-Proteins and Proteomics 1774, 403-411

51. Lee, C. (2010) 1-Anilinonaphthalene-8-sulfonate (ANS); a versatile fluorescent probe from protein folding study to drug design. BioWave 12, 1

52. Trent, J. D. (1996) A review of acquired thermotolerance, heat-shock proteins, and molecular chaperones in archaea. FEMS microbiology reviews 18, 249-258

53. Yaoi, T., Kagawa, H. K., and Trent, J. D. (1998) Chaperonin filaments: their formation and an evaluation of methods for studying them. Archives of biochemistry and biophysics 356, 55-62

54. Trent, J. (1993) Heat shock in thermophilic archaebacteria: the discovery of a new molecular chaperone in eukaryotes. JOURNAL-UOEH 15, 31-31

55. Kapatai, G., Large, A., and Lund, P. (2004) Keeping proteins on the straight and narrow: Molecular chaperones in the Archaea. The Biochemist 26, 22-25

56. Valle, F., Dietler, G., and Londei, P. (2001) Single-molecule imaging by atomic force microscopy of the native chaperonin complex of the thermophilic archaeon Sulfolobus solfataricus. Biochemical and biophysical research communications 288, 258-262

57. Trent, J. D., Gabrielsen, M., Jensen, B., Neuhard, J., and Olsen, J. (1994) Acquired thermotolerance and heat shock proteins in thermophiles from the three phylogenetic domains. Journal of bacteriology 176, 6148-6152

58. Large, A. T., Goldberg, M. D., and Lund, P. A. (2009) Chaperones and protein folding in the archaea. Biochemical Society Transactions 37, 46-51

59. Ceballos, R. M. (2017) Bioethanol and Natural Resources: Substrates, Chemistry and Engineered Systems.

60. Zhou, X.-X., Wang, Y.-B., Pan, Y.-J., and Li, W.-F. (2008) Differences in amino acids composition and coupling patterns between mesophilic and thermophilic proteins. Amino acids 34, 25-33

61. Freier, D., Mothershed, C. P., and Wiegel, J. (1988) Characterization of Clostridium thermocellum JW20. Applied and environmental microbiology 54, 204-211

62. Ng, T. K., Ben-Bassat, A., and Zeikus, J. (1981) Ethanol production by thermophilic bacteria: fermentation of cellulosic substrates by cocultures of Clostridium thermocellum and Clostridium thermohydrosulfuricum. Applied and environmental microbiology 41, 1337-1343

63. Verspurten, J., Gevaert, K., Declercq, W., and Vandenabeele, P. (2009) SitePredicting the cleavage of proteinase substrates. Trends in biochemical sciences 34, 319-323

64. Wrba, A., Schweiger, A., Schultes, V., Jaenicke, R., and Zavodszky, P. (1990) Extremely thermostable D-glyceraldehyde-3-phosphate dehydrogenase from the eubacterium Thermotoga maritima. Biochemistry 29, 7584-7592 
65. Gershenson, A., Schauerte, J. A., Giver, L., and Arnold, F. H. (2000) Tryptophan phosphorescence study of enzyme flexibility and unfolding in laboratory-evolved thermostable esterases. Biochemistry 39, 4658-4665

868 66. Arndt, C., Koristka, S., Bartsch, H., and Bachmann, M. (2012) Native polyacrylamide gels. in Protein electrophoresis, Springer. pp 49-53

67. Waterhouse, A., Bertoni, M., Bienert, S., Studer, G., Tauriello, G., Gumienny, R., Heer, F. T., de Beer, T. A. P., Rempfer, C., and Bordoli, L. (2018) SWISS-MODEL: homology modelling of protein structures and complexes. Nucleic acids research 46, W296-W303

68. Guex, N., Peitsch, M. C., and Schwede, T. (2009) Automated comparative protein structure modeling with SWISS-MODEL and Swiss-PdbViewer: A historical

perspective. Electrophoresis 30, S162-S173

69. Robert, X., and Gouet, P. (2014) Deciphering key features in protein structures with the new ENDscript server. Nucleic acids research 42, W320-W324

70. Gosh P, Kumar VG, Moradi M, and Ceballos RM (2021) Archaeal chaperonin structural perturbations under different $\mathrm{pH}$ and temperature conditions: A Molecular Dynamics Simulation [under review in Protein Science; see https:/www.biorxiv.org/content/]

71. Adnan Alrubaye, Nour Fatema, Chang-Hao Wu, Amy Eggers, Chinnapong Wangnai, Pablo Soraire, Guillermo DeBoeck and Ceballos RM (2021) Mobile Enzyme Sequestration Platform (MESP) nanotechnology for protecting enzyme supplements in chicken feed. [under review in J. Poultry Science; see https://www.biorxiv.org/content/] 